\title{
Transference of Emotional Intelligence and Self-Efficacy Observed Through Adventure West Virginia Student Trip Leaders
}

Ashley Irene Fox

West Virginia University, aif0001@mix.wvu.edu

Follow this and additional works at: https://researchrepository.wvu.edu/etd

Part of the Leadership Studies Commons, Leisure Studies Commons, and the Sports Studies Commons

\section{Recommended Citation}

Fox, Ashley Irene, "Transference of Emotional Intelligence and Self-Efficacy Observed Through Adventure West Virginia Student Trip Leaders" (2021). Graduate Theses, Dissertations, and Problem Reports. 8003. https://researchrepository.wvu.edu/etd/8003

This Thesis is protected by copyright and/or related rights. It has been brought to you by the The Research Repository @ WVU with permission from the rights-holder(s). You are free to use this Thesis in any way that is permitted by the copyright and related rights legislation that applies to your use. For other uses you must obtain permission from the rights-holder(s) directly, unless additional rights are indicated by a Creative Commons license in the record and/ or on the work itself. This Thesis has been accepted for inclusion in WVU Graduate Theses, Dissertations, and Problem Reports collection by an authorized administrator of The Research Repository @ WVU. For more information, please contact researchrepository@mail.wvu.edu. 


\title{
Transference of Emotional Intelligence and Self-Efficacy Observed Through Adventure West Virginia Student Trip Leaders
}

\begin{abstract}
Ashley I. Fox
Thesis submitted to the Davis College of Natural Resources at West Virginia University in partial fulfillment of the requirements for the degree of Master of Science in Recreation, Parks, and Tourism Resources
\end{abstract}

Steve Selin, Ph.D., Chair

Dave Smaldone, Ph.D.

John Greene, M.S.

Recreation, Parks, and Tourism Resources

Morgantown, West Virginia

2021

Keywords: Outdoor Orientation; Leadership Development; Student Development; Outdoor Education; Outdoor Leadership; Emotional Intelligence; Self-efficacy

Copyright 2021 Ashley Fox 


\begin{abstract}
Transference of Emotional Intelligence and Self-Efficacy as Observed Through Adventure West Virginia Student Trip Leaders
\end{abstract}

\author{
Ashley I. Fox
}

Since the creation of university sponsored outdoor recreation trips, research studies have been conducted to examine the impact of this programming on participants. These studies have typically assessed impacts through measuring common components used to quantify overall leadership abilities such as emotional intelligence, self-efficacy, and transference. In this study, researchers utilized a quasi-experimental approach to attempt to measure the impact of leading outdoor orientation trips on leader ability to transfer leadership skills to other areas of life. A sample $(N=29)$ of undergraduate student trip leaders of West Virginia University's Adventure West Virginia (AWV) program was surveyed and divided into groups based on varying experience levels. These groups were based on experience related to physical time (number of seasons as a leader) and immersion (additional positions held within AWV). Researchers hypothesized that more experienced leaders would demonstrate higher levels of confidence and transference of skills. Fisher's Exact Tests was used to compare differences across groups. Results show that more experienced leaders believed their leadership skills are above average compared to other students at WVU. Cochran-Mantel-Haenszel Test was used to compare changes in groups' confidence in using skills during and outside of leading trips (transference). Results indicated that three skills were consistently the least transferred to settings outside of trip leading: managing my emotions, managing other's emotions, and setting and reviewing long term goals. Finally, Kappa Coefficient as a test of agreement and Bowker's Test of Symmetry were utilized to analyze transference of individual skills. The results show that in several cases, more experienced leaders were better able to transfer skills than their lesser experienced peers. The results also showed that leaders holding additional positions within the broader AWV program demonstrated significant transference of leadership skills compared to those that only led First Year Trips (FYTs). Limitations of the research study as well as implications for future research and practice are discussed.

Keywords: Outdoor Orientation; Leadership Development; Student Development; Outdoor Education; Outdoor Leadership; Emotional Intelligence; Self-efficacy 


\section{Table of Contents}

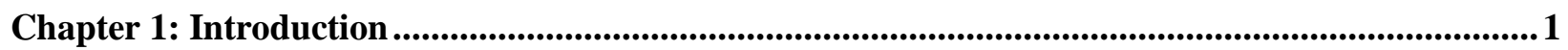

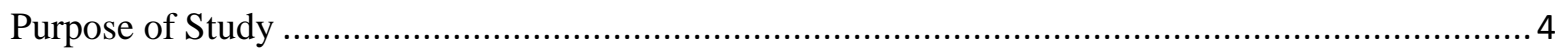

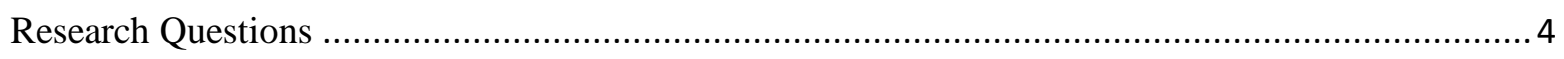

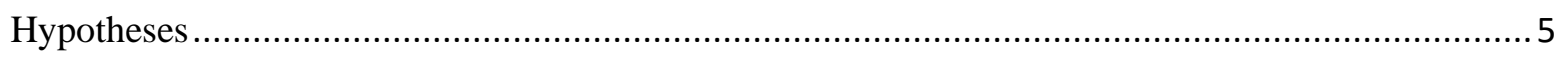

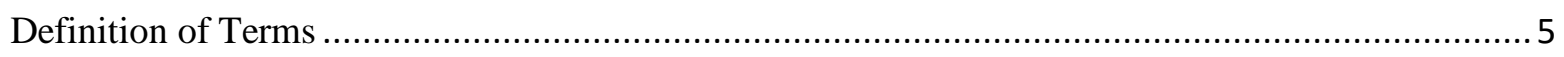

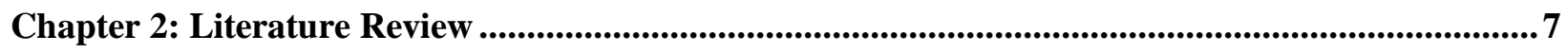

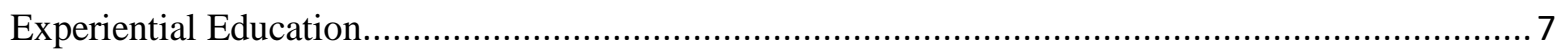

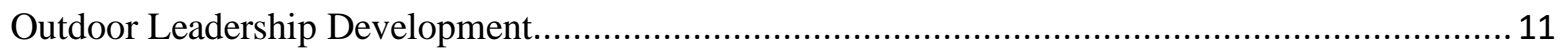

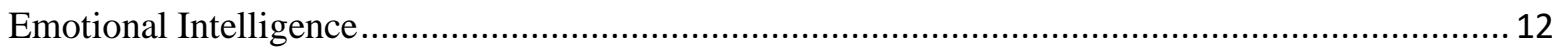

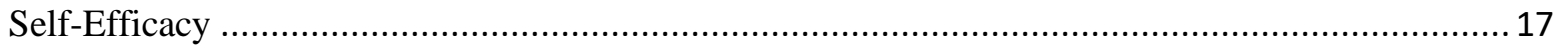

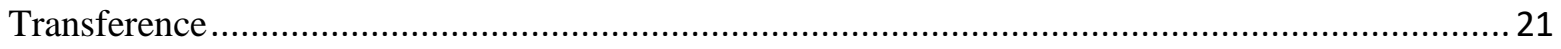

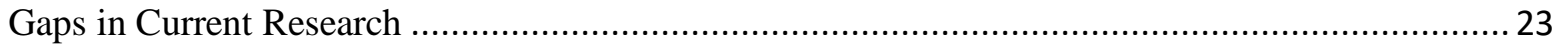

Chapter 3: Methodology ...........................................................................................................................24

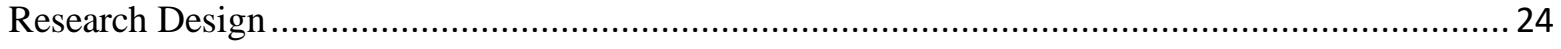

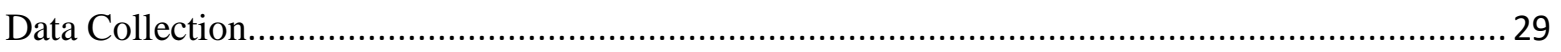

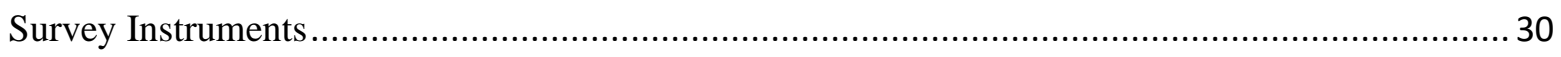

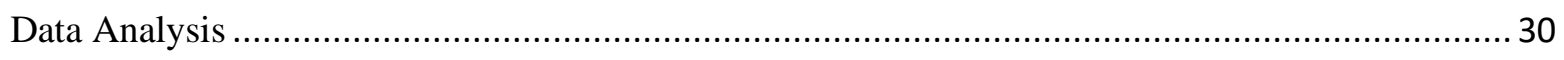

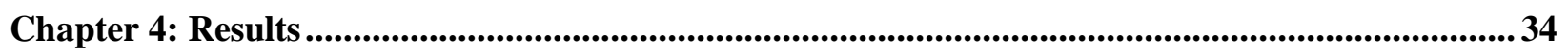

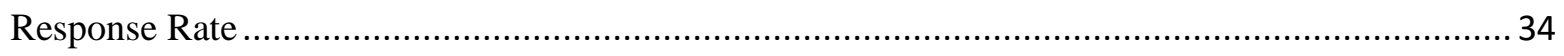

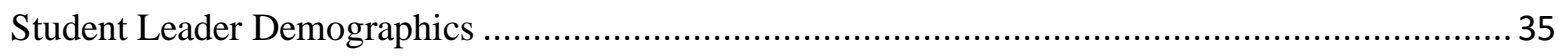

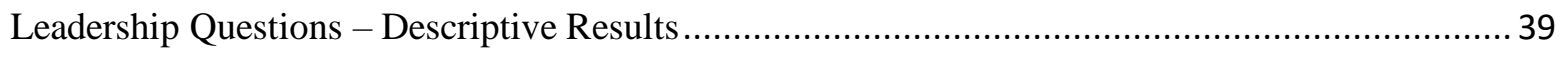

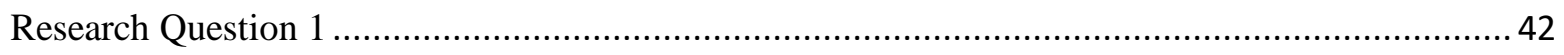

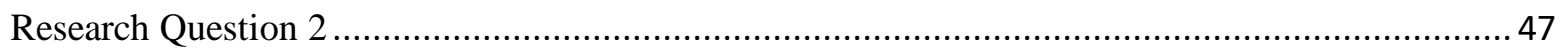

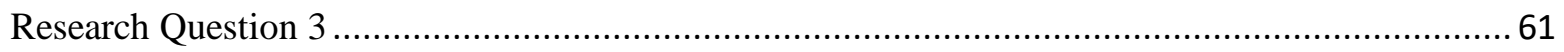

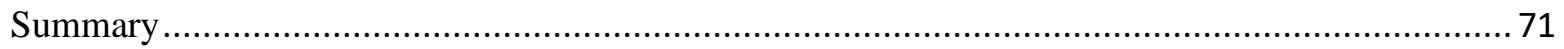

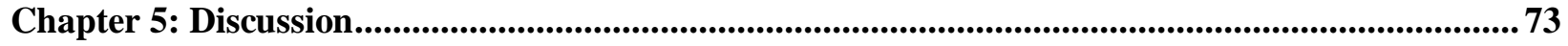

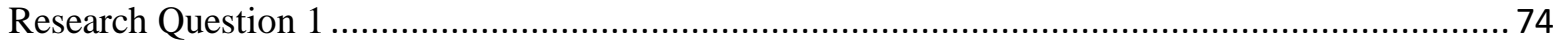

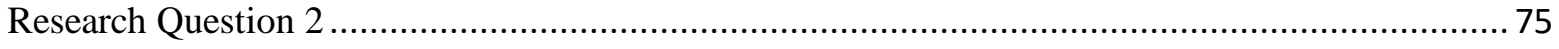

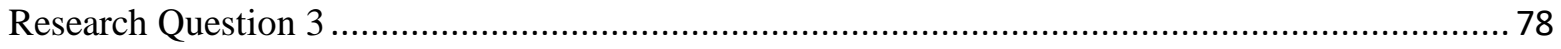

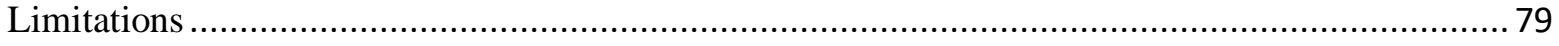

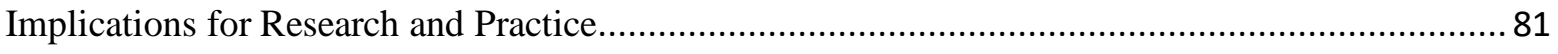

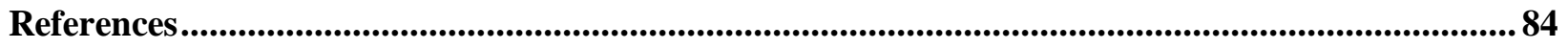

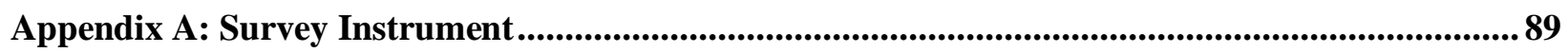




\section{Chapter 1 Introduction}

Outdoor leadership in an experiential education context is more than just knowledge and performance of technical skills. It is the combination of this with theory and social skills that include interpersonal communication, behavioral science, and emotional awareness (Dack, 2010). While experiential education participants grow in both technical and social skill areas during their experiences, social skills are what tend to transfer to other areas of life and remain with an individual for a longer period of time (Propst \& Koessler, 1998). The transference of these skills from the outdoors to daily life allow individuals to become more resilient when faced with new challenges. This provides strong reasoning for implementing experiential education programs into higher education settings (Bell \& Starbuck, 2017). Students that are more adaptable and resilient to challenge are better able to take on the difficulty of college than those who are not. Experiential education programs such as outdoor orientation programs have thus been shown to support higher retention rates and increased academic performance among firstyear college students (Bell \& Starbuck, 2017).

Experiential education is a philosophy in which educators purposefully engage with learners in direct experience and intentional reflection to increase knowledge, develop skills, clarify values, and develop people's capacity to contribute to their communities (Gass, Fillis \& Russell, 2012). With more higher education institutions recognizing the positive impacts of experiential education on student empowerment and retention, it is important to examine how these skills are obtained and later transferred to other aspects of life and the differences among students and their abilities to transfer those skills. The development of leadership skills in trip 
participants has long been a subject of research within outdoor journals (Propst 1998; Bell \& Starbuck, 2017). While there are several studies that examine the growth of leadership skills in student participants, there are few that investigate leadership development among student trip leaders themselves (Dack, 2010). This gap in research is emphasized further when considering how those trip leaders transfer their skills based on their level of experience.

Experiential education has theories based in several other historical sciences including physiology, ecology, psychology, sociology, and political sciences. Dewey along with Kurt Hahn with the Salem School in 1920 laid the groundwork for many experiential education theories we know and use today. In 1938, John Dewey released his work Experience and Education. Studying student development beyond the classroom, Dartmouth created the first outdoor orientation program for its incoming students. Several other outdoor leadership development programs came to fruition in the following decades, including Outward Bound in 1941 which played a pivotal role in the outdoor education movement, and helped set standards for adventure programming in terms of safety, program design, and leadership (Miner, 1999). From the fundamentals of Outward Bound grew the National Outdoor Leadership School (NOLS) in 1965. As of 2010, there are more than 164 outdoor orientation programs in the United States alone, with an average of ten new programs being created each year (Bell, Holmes, \& Williams, 2010).

In order to examine how well student trip leaders transfer skills from the outdoors to everyday society, we must take into account current higher education trends and culture. As the need for a college education becomes more common for job applicants, colleges have experienced the largest growth of student enrollment in history (Berger \& Lyon, 2005). In order to maintain certain institutional standards, colleges have become more selective of students they admit creating a new level of expectations for incoming students. This shift has put extra strain 
on students which combined with less financial support and student support programs, has led to a dramatic drop in student performance and retention. Most higher education institutions have found that it is more cost effective to retain students than replace those that withdraw, so to combat this drop, institutions have created new strategies to increase student retention (Berger \& Lyon, 2005). One of these strategies was to implement orientation programs, specifically outdoor orientation programs.

Outdoor orientation programs are experiences designed to assist incoming students in transitioning to college (Bell et al, 2010). These programs involve small groups of first-year students going on weeklong excursions that include adventure-based activities and are led by peer mentors. These programs instill a sense of place and belonging among their participants which plays a key role in student success (Strayhorn, 2012). With this supporting evidence, a majority of higher education institutions try to incorporate developmental growth as a goal of their programming (Bell et al., 2010). Institutions have also been interested in better preparing their students for careers post-graduation. Programs such as outdoor orientations not only help with student retention, but they instill qualities and skills that are highly transferable to students' work skillset which is even more reason to fund and implement them (Bell \& Starbuck, 2017).

The term leadership has gone through several iterations of constructs. Initially, leadership was linked to self-efficacy, itself a construct linked to three components: goal attainment, mentorship, and positive feedback (Propst, 1998). Self-efficacy refers to a person's belief in his or her ability to perform within a given domain effectively and it fosters leadership identity development (Bandura, 1977, 1986, Komives et al, 2006). Later, this construct of leadership came to include emotional intelligence, which is the ability to be aware of, control, and express 
one's emotions (Hayashi, 2006). Using these measurable constructs of leadership, studies have been done on experiential education participants and their leadership development.

\section{Purpose of Study}

Leadership qualities attained through guided outdoor experiences have been observed being transferred to other parts of the participants' lives and there is support that they are retained much longer than initially thought (Benson, 2018). However, more research on how these student leaders are transferring leadership skills to their daily lives can give key insight into how experiential programs benefit the student population and their local communities years down the road. This study will attempt to close the gap in current research by examining how well trip leaders are able to transfer their learned leadership skills to other aspects of life. Furthermore, this research will attempt to compare that level of transference among leaders of varying experience and program involvement. Background research for this study was used to examine three main content areas: 1) What leadership skills are the most transferable, 2) How are these skills measured, and 3) How is transference of these skills measured. Research results will provide techniques to facilitate higher levels of transference among student trip leaders in higher education institution outdoor programs.

\section{Research Questions}

In order to expand on current research of leadership growth in experiential education and outdoor orientation programs, researchers developed research questions that focused on leadership growth among student trip leaders at Adventure West Virginia. These research questions examine self-perceived emotional intelligence, self-efficacy, and transference.

R1) Does leading outdoor trips for Adventure West Virginia improve leaders' self-perceived emotional intelligence and self-efficacy across levels of experience with the program? 
R2) Do Adventure West Virginia leaders demonstrate a transference of leadership skills to areas outside of AWV across levels of experience with the program?

R3) Does the level of involvement across other Adventure West Virginia program areas impact leaders' ability to transfer leadership skills to life outside of AWV?

\section{Hypotheses}

In order to statistically test the above research questions, researchers developed three hypotheses that focus on student trip leader self-perceived emotional intelligence, self-efficacy, and transference. Null hypothesis were either accepted or denied, and are discussed in Chapter 4.

H1) Leaders with more experience leading First-Year trips will demonstrate higher levels of emotional intelligence and self-efficacy than leaders with less experience.

H2) Leaders with more experience leading First-Year trips will demonstrate a higher level of transference of emotional intelligence and self-efficacy to life outside of AWV.

H3) Leaders that hold additional positions within AWV will demonstrate a higher level of transference of emotional intelligence and self-efficacy to other areas of life than those that only lead First-Year Trips.

\section{Definition of Terms}

Experiential Education: Experiential education is a philosophy in which educators purposefully engage with learners in direct experience and intentional reflection to increase knowledge, develop skills, clarify values, and develop people's capacity to contribute to their communities (Gass, Fillis, \& Russell, 2012). 
Outdoor Orientation Programs: Also known as first-year experiences, these programs are designed to assist incoming students with their transition into college. These programs are designed for small groups of incoming students and include adventure-based activities that are led by peer mentors (Bell, Holmes, \& Williams, 2010).

Outdoor Leadership: Leadership is the capacity to move others towards goals shared with you, with a focus and competency they would not achieve on their own. The process of outdoor leadership includes learning, teaching, understanding, and facilitating safe group dynamics and problem solving in a wilderness setting (Graham, 1997).

Emotional Intelligence: The subset of social intelligence that involves the ability to monitor one's own, and others' feelings and emotions, to discriminate among them, and to use this information to guide one's thinking and actions (Salovey \& Mayer, 1990).

Self-efficacy: Personal judgements of one's capability to act in specific situations that may contain novel, unpredictable, and potentially stressful encounters (Bandura, 1977).

Transference: The outcomes that individuals gain from adventure education programs and apply to their everyday lives (Gass, 1999). 


\section{Chapter 2 \\ Literature Review}

The purpose of this literature review is to provide background information on the constructs that form the foundation for this research and show philosophical linkages between constructs. The review deals with the constructs of outdoor leadership development, emotional intelligence, self-efficacy, and transference. The literature review also documents the state of research in this area as well as gaps in this knowledge base.

\section{Experiential Education}

Experiential education is a philosophy and methodology that where educators purposefully engage with learners in direct experience and focused reflection in order to increase knowledge, develop skills, and clarify values (Cummings, 2009; Martin et al., 2006). This philosophy grew from the concept of outdoor education which combines adventure education and environmental education in order to concentrate around the interactions of people and the natural world (Martin et al., 2006). Looking at each of these bases specifically, adventure education is the personal and interpersonal relationships among people and providing opportunities for growth through adventure experiences that take place in the natural environment. These adventure experiences are mainly activities that employ risk and challenge in an outdoor setting and understands that change may occur in individuals or groups from direct

and purposeful exposure to challenge and adventure experiences. (Webb, 1999). A commonality among these experiences is that they all share exposure to the elements of uncertainty, real or perceived risk, excitement, interaction with nature, and effort (Raiola and O'Keefe, 1999). Environmental education is the process that allows individuals to explore environmental issues, engage in problem solving, and take action to improve the environment. As a result, individuals 
develop a deeper understanding of environmental issues and have the skills to make informed and responsible decisions. Combining these fundamental sciences, outdoor education is an experiential methods of learning that take place in the outdoors and is centered on the relationships between people and the natural environment.

The history of experiential education dates back to ancient Greek science, most notably stating with Plato and Aristotle (427-347 B.C.). Both believed that youth learn lessons of virtue best by being encouraged to participate in adventurous situations that required virtues to be exercised (Hunt, 1999). William James, a nineteenth century philosopher and psychologist, taught that adventurous situations utilizing nature as a medium were ideal in cultivating virtues in young people. Around the same time, the organized camping movement began by using adventure and nature as educational tools though expeditions, camping, and challenge activities (Raiola \& O'Keefe, 1999). The progressive education movement of the early 1900's was led by John Dewey and Kurt Hahn, who applied many of the ideas of early philosophers. Dewy released his seminal work Experience and Education (1938) and in conjunction Hahn began implementing those methods to practice through administering several schools on the basis of experiential and expeditionary style techniques (Greene, 2017). Thus developed "outdoor education: education in, about, and for the outdoors" (Raiola \& O'Keefe, 1999) and with is came several new outdoor education and experiential education programs including leading frontrunners Outward Bound and NOLS.

Outward Bound was founded by Kurt Hahn in 1941 as a training program for merchant seaman top teach survival skills and mold men into moral, good leaders for society (Miner, 1999). Participants in these trainings also gained self-esteem, discovered inner-strength and abilities, and developed a sense of responsibility towards others (Miner, 1999). The current 
educational approach of Outward Bound is an emphasis on high achievement through active learning, character development, and teamwork (Outward Bound Philosophy, 2021). A spinoff of Outward Bound with an emphasis in leadership development came the National Outdoor Leadership School (NOLS) in 1965 founded by Paul Petzoldt. Petzoldt saw a need for betterprepared leaders for outdoor education programming. The core curriculum that NOLS uphold to this day is safety and judgement, leadership and teamwork, outdoor skills, and environment studies. The focus of NOLS on developing high quality outdoor leaders has been the base for leadership training of most outdoor education organizations today. This includes leadership trainings in other sectors of society including executive challenge program and higher education outdoor programs.

Looking more specifically at the development of experiential education in higher education institutions, we must start with Dartmouth's outdoor orientation program that began in 1935. In 1951, Northern Illinois University, was the first university to offer outdoor education courses. These programs included elements of challenge, risk, group participation, cooperation, excitement, and skill development" (Raiola \& O'Keefe, 1999). Since then, several other higher education institutions have created outdoor education programs that offer their students knowledge, access, and support in the form of experiential education. This growth has led to the professionalization of experiential education and again the increasing need for highly trained leaders within these programs.

The benefits of experiential education programs on participants self-systems has been researched as far back as its founding. Self-systems include variables of self-concept, selfesteem, self-confidence, (Ewert and McAvoy, 2000) and have been found to show a positive and beneficial change for individuals that participate in experiential education programs. A study on 
Outward Bound participants found that their programs had a positive effect on participants' interpersonal skills, leadership skills, sense of empowerment, self-control, independence, assertiveness, decision making skills, and self-esteem (Hattie et al, 1997). Research also found that participating in these programs had positive effects on both group dynamics and development in the form of reciprocity, cohesion, and trust (Ewert \& McAvoy, 2000; Fielding \& Hogg, 1997). This supports the social learning theory that states humans learn by modeling or imitating other's behaviors as modeling by course instructors is vital to these programs' success (Bandura, 1969). This further supports the need for well-trained leaders of these programs.

Benefits of experiential education programs on higher education students mirrors those listed above, but it is important to look at their effects on student success and retention. Bell et al., 2014 found that outdoor orientation programs alone can increase student retention rates, and academic performance. Other positive effects include student extracurricular involvement, successful transition to college, community development, sense of place, self-concept, interdependence, self-satisfaction, self-confidence, and tolerance (Bell et al., 2017). of the key factors of this success is the sense of place and belonging that these orientation trips foster. Belongingness plays a key role in incoming student identity development because of the unique condition in which they find themselves (Greene, 2017; Baumeister \& Leary, 1995; Strayhorn, 2012). Neill, when examining the effectiveness of experiential education programs, proposed a list of twelve factors (Neill, 2007). The sixth factor that supports an effective program is carefully selected and trained leaders, and the seventh factor is the facilitation techniques of those leaders. The eighth factor is the group development, processes, and dynamics which are created and fostered by the leaders of that group. With a fourth of these factors involving leaders, 
it's important to not only research their development but attempt to understand the effects that leading these programs has on the trip leaders themselves.

\section{Outdoor Leadership Development}

Outdoor leadership is the area of leadership that involves purposefully taking others into the outdoors for recreation or education. Responsibilities of outdoor leaders include teaching skills, problem solving, ensuring group and individual safety, judgement making, and facilitating the philosophical, ethical, and aesthetic growth of participants (Ewert, 1989). It involves helping the individual or group identify goals and objectives, utilizing specific actions to achieve these goals, and creating opportunities for learning (Buell, 1983). When researching outdoor leadership, it is important to remember that it is a long-term, developmental process making its measurement obscure. Likewise, leadership development outcomes are contingent upon personality, situations, and behavioral characteristics. By measuring the outdoor leadership development of the participants, this study rather examines its hypothesized mediators: emotional intelligence, self-efficacy, and transference.

Outdoor leadership development is a major component of many outdoor education programs including Outward Bound, NOLS, Wilderness Education Association, and higher education outdoor programs. NOLS was the first program to specifically develop their training to create well-rounded outdoor leaders, and others seek to develop leadership skills in their participants that will be useful beyond the outdoor setting. Like NOLS and Outward Bound, most higher education outdoor programs recruit their leaders from participants that demonstrate leadership qualities early on. The transition from participant to peer leader is important because it is the stage of the largest shift in leadership identity. 
Outdoor leadership is a professional practice, and therefore the field upholds its leaders to high standards of quality and ethics. There are several versions of outdoor leadership foundations and competencies depending on the organization. Martin et al. (2017) list eight core competencies in outdoor leadership that mimic the majority of others. These eight core competencies include: Foundational knowledge, Self-awareness and professional conduct, Decision making and judgement, teaching and facilitation, environmental stewardship, program management, safety and risk management, and technical ability. In this study, we will focus on the growth of self-systems competencies including self-awareness in the form of emotional intelligence and decision making and judgement in the form of self-efficacy.

On this topic, Brent Bell and David Starbuck (2017) of Princeton University examined the positive impacts of outdoor orientation programming on student peer leaders. Using a mixedmethod study, they collected data from four different colleges with similar outdoor orientation programs. They found that the majority of surveyed students at all four colleges said that their leadership experience led to positive change including student leaders' belief in the outdoor leadership experience, increased confidence to face adversity, increased confidence in exercising one's voice appropriately, and increased leadership self-efficacy (Bell \& Starbuck, 2017). Where the gap in research still exists is in developing empirical support for the transference of these skills and the long-term effects they have on leaders' lives.

\section{Emotional Intelligence}

The concept of emotional intelligence evolved from the theory of social intelligence; the ability to understand others and to act or behave wisely in relation to others (Thorndike, 1920). A current definition of emotional intelligence is the ability to monitor one's own and others' feelings and emotions, to discriminate among them an to use this information to guide one's 
thinking and actions (Salovey and Mayer, 1990). Emotional intelligence contains several core skills such as knowing yourself, maintaining control in stressful situations, perceiving other accurately, and communicating with flexibility (Goleman, 2001). With a broadening of research on how leadership develops, emotional intelligence has become an increasingly viable construct for identifying potentially effective leaders as well as a tool for developing effective leadership skills (Palmer, Walls, Burgess, \& Stough, 2001). For the purpose of this study, we will be focusing on the concept of emotional intelligence as it can be applied to outdoor leadership.

While there have been several studies looking at the role of emotional intelligence among the business world, research that applies the concept to outdoor leadership is just emerging. Daniel Goleman, in his book What Makes a Leader? (1998) argues that emotional intelligence is a prerequisite and a necessity for success leadership. Jennifer M. George (2000) proposed that emotional intelligence contributes to effective leadership by focusing on essential elements of leader effectiveness. These include development of collective goals and objectives, such as instilling in others an appreciation of the importance of work activities; generating and maintaining enthusiasm, confidence, optimism, cooperation, and trust; encouraging flexibility in decision making and change; and establishing and maintaining a meaningful identity for an organization. The elements noted above are also present when examining the responsibilities and objectives of outdoor leaders in experiential education.

Looking more closely at the effects of emotional intelligence on leadership development within outdoor education, it is reasonable to assume that there is a positive mutual relationship between outdoor leadership and emotional intelligence. Beginning with a meta-analysis by Hattie, Marsh, Neill, \& Richards (1997), adventure programs were found to have a positive impact on leader's social competencies such as self-concept, assertiveness, achievement 
motivations, emotional stability, interpersonal skills, and flexibility, all components of emotional intelligence. In a study conducted by Cory Dack (2010), researchers found that outdoor leaders tend to have high levels of emotional intelligence and those that did are more likely to be better able to procure valuable experiences for their participants. This study utilized the Life Effectiveness Questionnaire (LEQ) developed by Neill and Richards (1997) in an effort to measure the life effectiveness of outdoor leaders. Life effectiveness is a person's capacity to adapt, survive, and thrive (Neill, 2007). Dack's questionnaire included open-ended questions meant to prompt research participants to examine and reflect upon their experiences as wilderness adventure leaders. All subjects experienced an increased life effectiveness revealing that positive human transformation can occur in the right wilderness adventure setting. Answers from the open-ended questions in Cory Dack's study (2010) revealed that certain kinds of experiences supported specific components of emotional intelligence and leadership. These experiences include debrief \& feedback, leadership roles, challenging experiences, entire expedition experience, and evaluations \& assessments.

Studies have found that emotional intelligence has been a strong predictor variable of transformational leadership, self-efficacy, life satisfaction, and academic success (Hartsfield, 2003; Ciarrochi et al., 2000; Parker, et al., 2004). Likewise, evidence supports that emotional intelligence may influence major life outcomes including academic performance (Parker et al., 2004), positive interactions with others (Lopes et al., 2003), life satisfaction (Ciarrochi et al., 2000), leadership (Hartsfield, 2003; Kobe al., 2001; Schulte, 2003), and team performance (Prati, et al., 2003). While the above effects are important for any leadership role, they are also beneficial to the general population and could be increasingly helpful to our current population of college students. According to Grandey (2000), burnout is a long-term consequence that 
affects individual well-being due to difficulties in regulating emotions during tasks that produce strong emotional responses. Outdoor leaders can be extremely susceptible to this burnout due to the highly emotional and stressful aspect of outdoor programs. The combination of extended, effectively charged, and intimate nature of outdoor education and travel can amplify the emotional labor and fatigue of leaders. Combine this with the residual stress of being a college student, and it's no wonder that developing leader's emotional regulation could be beneficial not only to the individual leaders but the programs they work for.

Methods to measure emotional intelligence characteristics has been explored since the 1990’s (Mayer et al., 2000). Most methods fit within two models: ability models or mixed models. Daniel Goleman, author of Emotional Intelligence, and his colleagues developed a multi-rating measurement for emotional intelligence, Emotional Competence Inventory (ECI). This measurement system examines four aspects of emotional intelligence: self-awareness, selfmanagement, social awareness, and social skills. It relies on participants giving objective information about their own ability rather than attempting to measure actual ability, which can be advantageous as it reduces impacts of social desirability (Hayashi, 2006). Mixed models focus more on the actual ability of the participant and include that of Salovey and Sluyter (1997) where they attempt to measure emotional intelligence using the Multifactor Emotional Intelligence Scale (MEIS). The MEIS consists of twelve ability measures that test one's capacity to reason about emotions, and of emotions to enhance thinking.

Martin et al (2006) discussed the importance of emotional intelligence for outdoor leaders in understanding the motivations, attitudes, and behaviors of program participants. Previous research has found correlations between emotional intelligence when it comes to leadership experience and training, which supports the idea that emotional intelligence may be a trait that 
can be learned (King, 1999; Purkable, 2003). A notable trend that has been shown among research in this area is that several studies have found a correlation between emotional intelligence levels and amount of leadership experience. Aguiar (1986) compared selected characteristics, such as leadership opinions, personality characteristics, vocational/leisure interests, age, education, experience, and gender, of more successful adventure leaders with those of less successful leaders. The results showed that more successful leaders had more years of education and higher levels of experience. Hayashi and Ewert (2006) examined outdoor leaders' emotional intelligence and also found that leaders who had more overall outdoor experience reported higher levels of emotional intelligence, especially with intrapersonal components. They also found that leaders who had taught various kinds of outdoor activities were found to have higher levels of emotional intelligence and transformational leadership. A similar trend was found when Jacobs (2004) examined the effect of summer camp employment on emotional intelligence scores and found that scores significantly increased through summer camp employment and amount of experience. The components of intrapersonal, interpersonal, stress management, and general mood all showed significant increases among returning staff members (more experienced staff) versus first-year staff members. The trend of leaders with more experience demonstrating higher levels of emotional intelligence supports the research of this study.

Specifically, due to the conceptual relatedness, emotional intelligence has been discussed as an important component of transformational leadership. Seltzer and Bass (1990) proposes that transformational leaders must possess social and emotional intelligence in order for them to inspire participants and build relationships. Barling et al. (2000) asserted three reasons why individuals with high emotional intelligence would be more likely to make an impact on their 
participants. First, leaders who know and can manage their own emotions, and who display selfcontrol, could serve as role models for their followers, thereby enhancing followers' trust in and respect for their leaders. Second, with an emphasis on understanding others' emotions, leaders would be better able to realize the extent to which participants could be inspired, motivated, and impacted. Third, with leaders' ability to understand followers' needs and interests, and with its emphasis on empathy and the ability to manage relationships positively, leaders would be better suited to manifest individual consideration.

In a study by Ayako Hayashi (2006), the impacts of an outdoor leadership program on the development of emotional intelligence and leadership were examined. An effort was made to understand the relationships among emotional intelligence, transformational leadership, and outdoor experience. Transformational leadership is a high level of leadership where leaders are better able to raise participants' consciousness levels about the importance and value of designated outcomes and way of achieving them (Bass, 1990). This concept is closely related to transference that will be discussed later on. In his study, Hayashi found a positive correlation between emotional intelligence and transformational leadership. The use of surveys in this study proved beneficial for measuring the emotional leadership and self-confidence components of leadership. These studies provide a link to explain the connection between emotional intelligence, self-efficacy, and transference.

\section{Self-Efficacy}

Self-efficacy has roots in social learning theory and is known as the perception of what we as individuals believe we can or cannot do (Martin et al., 2006). Bandura's (1977) goes on to say self-efficacy refers to personal judgements of one's capabilities to act in specific situations that may contain novel, unpredictable, and potentially stressful encounter. This conceptual 
framework is utilized by several fields to understand behavior and explain success and/or continued participation in a variety of domains, some of which include achievement, high-risk sports, career development, pain tolerance, and leisure socialization (Propst and Koessler, 1998) These studies show that self-efficacy has a positive impact on individual success, selfconfidence, and future development.

Self-efficacy growth is based on four principal sources of information: performance attainment, vicarious experiences, psychological states, and verbal persuasion (Bandura, 1977). The most influential of these on efficacy strength is performance attainment. Attempting a new challenge and succeeding increases one's confidence in achieving similar challenges in the future. Likewise, successes in skills increase efficacy judgements, which repeated failures lower them. When experiencing a new challenge, individuals tend to rely on information from past performance to judge their emotions and physiological capabilities (Propst and Koessler, 1998). When in a new setting which limited previous experience, participants are faced with even more stress. While anxiety provides the potential for enhanced self-efficacy and performance, too much of it will force participants to find themselves in levels of distress that debilitate future actions. This anxiety can be lessened via modelling by a leader or peer to give a frame of reference of what is expected. Experiences that eliminate debilitating anxiety can heighten selfefficacy and improve overall performance (Bandura, 1986).

By supporting the components of self-efficacy including mentorship, feedback, and goal attainment one can positively increase self-efficacy in others (Jeruchim \& Shapiro, 1992; Bandura, 1977). The connection of these components to continued participation in outdoor leadership development opportunities created a positive feedback loop (Propst and Koessler, 1998). Continued participation in these growth opportunities is considered the pre-cursor to 
leadership which is important to note when studying leadership development. The higher one's self-efficacy when participating, the more likely they are to pursue leadership opportunities (Propst and Koessler, 1998).

Examining mentorship as a component of self-efficacy, this study will focus on the participant-instructor relationship. In this relationship, the leader not only acts as a mentor but as a role model that exhibits behaviors, values, professionalism, and competence that inspires the mentee to look up to and admire (Jeruchim \& Shapiro, 1992). In outdoor education, this relationship encourages the establishment of goals, offering guidance on continued performance, and providing periodic feedback (Propst and Koessler, 1998). Feedback also impacts selfefficacy and is a major component of experiential education. Feedback can improve selfefficacy when given in situations when participants are unable to judge their own performance (Bandura, 1986). If feedback is delayed beyond the point of remembering the behavior, then individuals do not benefit from that feedback (Rink, 1985). Bandura and Schunk (1981) agree that pursuing proximal goals and achieving them increases self-efficacy and motivation. All of these components of self-efficacy are present in an outdoor education setting and can be instilled via leadership training. For this study, we will be focusing on goal attainment as a means to measure self-efficacy.

Gager's model of the experiential learning process (1977), support the idea of selfefficacy in an outdoor context, where the learner is placed in a demanding situation where action and decision-making are required. Succeeding at a new skill was necessary, which helped satisfy ego needs and self-esteem. The learner then faced a similar challenge, and afterward, allowed to reflect on their performance and connect the experience to a broader range of experiences. If and when the challenge is accomplished, individuals reflect on what they learned about themselves 
and how it could be applied to other life experiences. This helps transfer those skill to other areas of life thus connection self-efficacy to transference.

A study by Propst and Koessler (1998), found that for NOLS programs, self-efficacy not only improved over the course of the program, but resided within participants up to one year after. They also found that the type of feedback given to students throughout the course is important for enhancing self-efficacy and differed among genders. Positive feedback was more important for females while immediate feedback was more important for males when examining short-term self-efficacy. These findings support the idea that when it comes to general longevity, emotional intelligence outlasts self-efficacy.

When discussing self-efficacy, we must also examine self-confidence (Benson 2018). In an outdoor leadership development perspective, leaders who are high performers are competent and confident in their ability to influence the behaviors, attitudes, and values of themselves, other individuals, groups, and organizations (Benson, 2018). Leadership training and development, therefore, involves improving both the competence and the confidence of leaders, enabling them to move from low performance to high performance. Benson (2018) conducted a study to determine if youths' leader confidence, once developed in a leadership training program, persisted over time. He compared two studies of how leadership skills last in an individual's frame of mind and impacted their actions and came to the conclusion that that leader effectiveness and leader self-confidence can be developed in youth through leadership training programs and if the right conditions are met, these attributes will persist over time. His second conclusion supported that of Kirkpatrick and Locke's (1991) emphasis that self-confidence is a necessary trait for successful leadership and needs to be one of the major objectives of leadership training programs. This provides support for McCormick's (2001) request to use leadership, self- 
efficacy, or self-confidence as a training evaluation criterion. These findings show the importance of active leadership training in the development of social skills in the field. Likewise, the quality of these trainings determines how long these qualities are carried within an individual.

\section{Transference}

Previous research has documented the immediate outcomes associated with participation in outdoor education, but few have documented the transference of long-term outcomes (Goldenberg et al., 2005; Sibthorp et al, 2008). It can be difficult to measure how certain leadership skills and qualities last over time and leak into one's community due to the vague nature of skill measurement. The concept of transference is at the heart of the debate concerning the effectiveness of wilderness adventure education programs as a viable and reliable form of education (Cummings, 2009). As Gass (1999) stated, "the true value or effectiveness of the program lies in how learning experienced during the adventure activity will serve the learner in the future." Another factor of Neill's (2007) twelve factors that determine an effective outdoor education program is the use of experiential and consequential problem-solving tasks, offering hands-on and concrete tasks with real world constraints. The ninth factor is programming for transferability, including teaching skills directly applicable to everyday life, and looking for metaphoric structures that relate back to home life.

As stated with self-efficacy, once an individual actively reflects on their experience, they are able to internalize it and transfer it to other part of life (Cummings, 2009). Kolb's (1984) experiential learning cycles expands on Gager's by adding that observations are assimilated into a "theory" from which new implications for action can be deducted. These serve as guides for new experiences and have the potential to change future values and behavior (Cummings, 2009). 
By putting more emphasis on group processing and discussions, leaders are able to guide participants through that reflection increasing the chances for transference (Bacon, 1990). It's also important to note that the level of transference may vary depending on the social environment the participant finds themselves in. For example, their transference of self-efficacy of a certain task may not be as strong within their family context as a close friend context.

Emotional intelligence and self-efficacy are just two of the indicators that allow researchers to measure transference, and one tends to always impact the other. For example, sense of accomplishment helped many participants to feel motivated to transfer course benefits and outcomes into their lives. Aspects of participants' lives affected by this transference of course outcomes included greater self-respect/esteem/confidence. This led to some participants experiencing more fun and enjoyment of life and a greater number of experienced warm relationships with others. Warm relationships with others led to a sense of belonging and greater self-awareness (Cummings, 2009).

In an attempt to measure transference in outdoor leadership, much of the research has examined the retention of specifically targeted outcomes after course completion. Studies examining the transference of emotional intelligence and self-efficacy after significant time passed post program found that participants were able to transfer the skills they learned to other areas of life (Marsh et al., 1986; Propst and Koessler, 1998; Paxton \& McAvoy, 2000; Kellert,1999; Sibthorp et al., 2008, Benson, 2018). Sibthorp et al. was the only study that examined lingering transference for more than a year and found that participant's learned skills remained relevant for years after the course, especially in areas that included a greater appreciation of nature; desire to be in the outdoors; outdoor skills; ability to get along with 
different types of people; ability to serve in a leadership role; and self-confidence. These areas of awareness correlate to objectives in the training of emotional intelligence and self-efficacy.

\section{Gaps in Current Research}

While there is a strong base for research on leadership development that focuses on emotional intelligence, self-efficacy, and the transference separately, there is a lack of research on how those specific skills are attained and transferred by outdoor orientation student trip leaders. Looking more specifically at similar research done on the AWV student population, Coy James Belknap conducted research in 2011 on the impacts of the outdoor orientation program on student participants' self-evaluated trait emotional intelligence. Using pre-test and post-test values, he attempted to measure trait emotional intelligence (TEI) which was initially introduced by Petrides in 2001. TEI, also known as emotional self-efficacy, describes "our perceptions of our emotional world: what our emotional dispositions are and how good we believe we are in terms of perceiving, understanding, managing, and utilizing our own and other people's emotions (Petrides et al, 2018). In other words, TEI is the subcategory of EI that involves measurements being self-perceived. It's sibling, Cognitive Emotional Intelligence, concerns the actual abilities held within any given individual (Petrides \& Furnham, 2001). Belknap's results found that TEI can be raised, especially in relation to outdoor based collegiate orientation programs (2011). Following this research path, this study further examines the impacts of these programs on TEI, both emotional intelligence and self-efficacy, on student leaders within the Adventure WV program. 


\section{Chapter 3 \\ Methodology}

The purpose of this study is to determine if leaders with more experience within the Adventure West Virginia program demonstrate higher levels of emotional intelligence and selfefficacy. In addition, this study is designed to compare new versus return leaders' ability to transfer these leadership qualities to other aspect of life. This chapter reviews the scope of the study; the description of the population sample; procedures used to measure data; methods used to analyze the data; and validation criteria for the methods used.

\section{Research Design}

To test the effectiveness of leadership trainings and the actual leadership experience obtained through AWV, researchers examined previous and current FYT leaders with a varying leadership experience. Leaders that actively worked during the summers of 2017, 2018, and 2019 were asked to quantitatively rank and compare their leadership skills to other WVU students as well as examine how effectively they have transferred those skills to other areas of life. This sampling time frame was chosen to compare leaders that received similar leadership trainings. Leadership components that were compared included self-perceived emotional intelligence, selfefficacy, and transference. This methodology was based on Prospt's (1998) research indicating that self-efficacy had a direct, positive correlation with leadership abilities. It also uses similar methodology to Hayashi's (2006) study of emotional intelligence development among experiential education trip leaders and Daniel Goleman’s (2001) Emotional Competence Inventory (ECI). Questions concerning EI and SE were modelled after Petrides's Trait Emotional Intelligence Questionnaire (TEIQue, 2009). Survey questions cover the sampling domain of the construct comprehensively and are shown in Table 1. A goal of this study was to use a survey 
that was easy to complete to encourage survey participation, and for the survey to be properly and fairly distributed to the sample. Additionally, this pilot study served to test the correlations between leader experience and leadership qualities as well as the framing and wording of the questions to be utilized in an extended study.

\section{Table 1}

Characteristics of Emotional Intelligence (EI) and Self-Efficacy (SE)

\begin{tabular}{ll}
\hline \hline Skill & Characteristic \\
\hline Emotional Intelligence & \\
Emotion Perception & Understanding my own and others' emotions \\
Emotion Expression & Managing my own emotions \\
Emotion Management & Manage others' emotions \\
Self-efficacy & \\
Self-Motivation & Set short- and long-term goals \\
Stress/Goal Management & Set long term goals and review my progress regularly \\
\hline
\end{tabular}

Characteristics taken from the Trait Emotional Intelligence Questionnaire (TEIQue) (Petrides, 2009)

\section{Sample Population}

To answer the research questions for this study, West Virginia University students that led First Year Trips programs for Adventure West Virginia during any of the summer seasons between 2017 and 2019 were asked to participate. While this time frame consists of three separate FYT seasons that each had their own leadership trainings, a larger sample was required to look at skill levels across work experience.

In order to understand the results of this study, we must first have a solid understanding of the First-Year Trips program within AWV. The Adventure West Virginia program was 
created in 2004 beginning with a single trip of 12 students. Now one of the largest collegiate outdoor adventure programs in the country, AWV offers over 50 trips that hosts over 1,200 incoming students over a summer. Adventure WV First-Year Trips are peer-led adventure-based experiences that prepare students for life at West Virginia University (WVU). Trips offer participants diverse opportunities to meet other first-year students, learn about themselves, and connect with WVU. Trips are 5-6 days long and consist of varying outdoor activities such as rock climbing, whitewater rafting, backpacking, community service, high-ropes course, and teambuilding. Normally the cost of these programs runs between $\$ 400-\$ 500$, but with major university support, AWV now provides these trips to students for a subsidized $\$ 95$. This cost can further be completely covered based on individual students' financial aid needs.

While there are several unique trip models that students can choose from, all FYT's have a standardized curriculum that help meet AWV's goals of better preparing incoming students for college. For technical skills, leaders teach students how to succeed in the outdoor sports they are participating in, such as rock climbing, white water rafting, backpacking, and high ropes courses. While these activities provide a fun, new learning environment that pushes students out of their comfort zone, the goal is that these experiences prepare the group for self and group reflection in other team discussions.

Student leaders facilitate daily debriefs, gratitude circles, evening expectations and morning reminders, a full value contract, and solo reflections. Students are required to keep a journal throughout the trip, that their leaders check for completion and progress. Also, each night has an intentional discussion pertaining to life as a new college student. These discussions include making the transition to college, resources for success, diversity and inclusion, and how to make healthy decisions. Other topics covered are those that help develop a sense of belonging 
among students and include WVU history and traditions. Students are asked to write down their goals for themselves for their first year of school as well as how they think they will achieve them. Leaders provide mentorship to the students as they decide action plans to stick to while in school.

Student participation and support continues after the trip ends, as student are required to participate in a one-credit hour course during their first semester. Throughout the course, students are asked to follow-up on the goals they set for themselves and benchmark their progress. They are also asked to reflect on what they learned on their trip and how they could apply that to life at school. If participants were highly impacted by the experience and leaders on their trip, they may be interested in applying for a leadership position. The FYT leader application process takes place over the fall semester. These applicants participate in group interviews and if they do well, are later asked to return for individual interviews. If they are accepted, students then take a three-credit hour course offered through the Recreation, Parks, and Tourism Resources Department called Leadership in Experiential Education (LEED).

The LEED course covers topics that prepare students to lead in an experiential education setting, specifically leading for AWV. Curriculum includes outdoor education theory and practice including history of experiential education, communication and relationship management, facilitation design, delivery, and processing, Leave No Trace, group development, situational leadership, expedition behavior, risk management, conflict management, outdoor ethics, understanding and responding to mental health concerns, and maximizing inclusivity. Several of these topics are covered in similar trainings and trip curriculum mentioned above in programs such as NOLS and Outward Bound. After completing the course, contracts are offered to applicants that showed excellence in the course. Once hired, these students are also required to 
obtain their Wilderness First Aid (WFA) certification which is also a course offered through WVU and instructed by AWV.

After students complete all course work required for them to lead FYTs, they participate in an in-person training trip that takes place in May just before the summer season begins. These training trips are led by AWV professional staff and include an intentional curriculum of technical skills and social skills while in the field. These training trips allow student leaders to apply the theories they learned in the LEED course to an outdoor setting among a group of peers. This allows professional staff to examine how well student leaders transfer their learned skills to a potentially stressful setting, and they observe overall group dynamics as well as individual leader skills and competencies.

Due to the large amount of student trip leaders each summer and the variety of FYT trips offered, student leaders are split in to two groups for training and work: frontcountry and backcountry. Frontcountry leaders are trained in a higher level of group facilitation as well as a variety of technical skills relative to working at height such as rock climbing and high-ropes courses. Backcountry leaders are trained in a higher level of backpacking technical skill facilitation and emergency evacuation procedures.

Each trip has 2-4 trip student trip leaders that act as peer mentors and facilitators to student participants. The number of trips a student leader works over the course of a summer depends on their availability and trip enrollment. Leaders are required to have group meetings before, during, and after each trip to discuss specific trip goas, issues that arise, and selfreflection. After each trip, leaders are required to give each other feedback on what they did well or could improve upon. If leaders decide to return, the following year to lead again, they get a 
refresher in course content by participating in the training trips. Return leaders also have more opportunities to express interest in certain trips they may want to lead. Returning student leaders can also enroll in the Expeditionary Planning and Education in the Outdoors (EPEO) course over the spring semester. This course covers more in-depth training to experiential education leadership with topics including adaptive dissonance, adventure-experience paradigm, decisionmaking, legal liability in the outdoors, and more difficult technical skills.

After completing their first summer, student leaders also have the opportunity to begin working for other areas of AWV. Depending on their own interests and skill set, they could seek employment at the Outdoor Recreation Center that includes program support and outdoor gear rentals, the Outdoor Education Center with high and low ropes courses and a canopy tour, the indoor climbing wall at the Student Recreation Center, or continued leadership opportunities throughout the semester as weekend trip, skills workshops, or break trips.

\section{Data Collection}

All student leaders that actively led FYTs during the summer seasons of 2017, 2018, and 2019 were asked to voluntarily participate in this study. The survey consisted of an electronic Qualtrics questionnaire split into three parts: demographics, leadership experience, and leadership ability. While this study does not replicate exact methodology of another study, individual questionnaire items were adapted from previous research studies in order to accommodate the study for AWV's unique outdoor orientation program and its student leaders. The questions measuring emotional intelligence and self-efficacy were modelled after studies done by Hayashi, 2006; Goleman, 2001; Propst, 1998; and Bell and Starbuck, 2017. Models of measuring transference include that of Marsh, 1986; Propst and Koessler, 1998; Benson, 2009; and Sibthorp, 2018. All surveys were administered in email form. The benefits of administering 
the survey via email, includes allowing researchers to reach previous leaders regardless of geographic location, as well as ensure that the tone and phrasing of the questions remains consistent to all participants. While this method does not allow for deviation due to serendipitous findings, the goal of utilizing constructs from past research was to effectively examine the potential correlation of student leaders' experience leading outdoor trips with their leadership growth and transference.

\section{Survey Instruments}

In the fall of 2019, researchers sent out the Qualtrics survey via email to AWV leaders that were active between 2017 and 2019 summer seasons. The survey consisted of seven questions regarding respondent demographics and leadership experience as well as seven questions that measured self-perceived emotional intelligence and self-efficacy. For those questions, Likert scales were utilized to allow for answer diversity to limit ceiling-effect when interpreting results of self-perceived leadership skills, emotional intelligence, self-efficacy, and skill transference. All data were collected in adherence to Institutional Review Board (IRB) requirements, and the survey was piloted by sending to AWV professional staff for feedback.

\section{Data Analysis}

After quantitative data were collected, responses were coded and entered into JMP and SAS software (JMP®, Version Pro 14.0, SAS Institute Inc., Cary, NC, Copyright @2015; SAS®, Version 9.4, SAS Institute Inc., Cary, NC, Copyright (O2002-2012). Specific data analyses include the following statistical analyses: Independence of two categorical nominal variables were tested using Fisher's Exact Test. Fisher's exact test is similar to Pearson's Chi-square test of independence and is used when more than $20 \%$ of combinations have expected values (counts) smaller than five, which was often the case, with overall sample size of $n=29$. In the 
case when the response variable was an ordinal scale with three or more levels (Likert scale), Cochran-Mantel-Haenszel Test (CMH) was utilized (Stokes, Davis, and Kock, 2012). In addition, $\mathrm{CMH}$ was used to test if leaders' confidence in their abilities were similar during and outside of FYTs while controlling for leadership experience level (new and return; just leader and more). To prevent excessive Type I errors from using multiple Fisher's exact analyses (73 analyses). Benjamini-Hochberg test was completed on p-values using a false discovery rate of 0.3, in order to correct for type I errors (Benjamini-Hochberg, 1995).

An agreement analysis (Kappa) of leaders' confidence in their ability to use skills between during and outside FYTs was utilized to assess and estimate skill transference, regardless of overall confidence levels. For example, confidence scores of leaders' ability to read others' emotions were organized within a $3 \times 3$ contingency table, where scores $(1=$ Not True, $2=$ Somewhat True, and 3 = Very True) "during FYTs" are rows and "outside FYTs" are columns. If leaders that are not confident in this skill while leading FYTs (1) also indicated so outside of leading FYTs $(1)$, the count for the corresponding cell $(1,1)$ in the contingency table will be high relative to the sample. In a similar fashion, if the leaders that are somewhat confident in this skill (2) are also showing similar levels of confidence outside of leading FYTs (2), the number at the intersection $(2,2)$ is going to represent them. Finally, if the leaders that indicated they were more confident in their ability to read others' emotions (3) also reported a similar confidence outside of leading FYTs (Very True), the corresponding cell within the contingency table $(3,3)$ will be high relative to the sample. Such a pattern creates a strong diagonal $(1,1 ; 2,2 ; 3,3)$ with respect to the entire sample within the contingency data matrix, and this strength of the diagonal is indirectly measured by Kappa statistics. The Kappa coefficient measures the amount of agreement beyond that expected by chance (Cohen, 1960; Stokes, Davis, and Kock, 2012). 
Kappa equals 1 when there is perfect agreement and equals 0 when the agreement equals that expected by chance. Kappa coefficient values below 0.4 indicate a slight agreement, values 0.4 and above are considered moderate agreement, and values 0.8 or higher indicate excellent agreement (Cohen, 1960). The agreement test was completed for the entire group of leaders, as well as after dividing the group by their leadership experience (both time and immersion).

Bowker's Test of Symmetry (also known as McNemar's test for 2x2 contingency tables) was an additionally valuable tool to assess if the disagreement of skill levels was symmetrical. For example, symmetry would be observed if a similar number of leaders reported high confidence in certain skills during FYTs and low confidence outside of FYTs as the number of leaders that reported the inverse, low confidence during FYTs and high confidence outside of FYTs. In other words, if the data of the main diagonal were equally distributed on both sides of the diagonal, that would be the evidence of symmetry. Significant asymmetry is evidence that skills are higher during the trips, for but not outside FYTs. 
Table 2. Research Questions, Correlating Variables, and Statistical Analyses

\begin{tabular}{|c|c|c|c|}
\hline Research Question & Hypothesis & Variables & Analyses \\
\hline $\begin{array}{l}\text { R1) Does leading outdoor } \\
\text { trips for Adventure West } \\
\text { Virginia improve leaders' } \\
\text { self-perceived emotional } \\
\text { intelligence and self-efficacy } \\
\text { across levels of experience } \\
\text { with the program? }\end{array}$ & $\begin{array}{l}\text { H1) Leaders with more } \\
\text { experience leading First - } \\
\text { Year trips will } \\
\text { demonstrate higher levels } \\
\text { of emotional intelligence } \\
\text { and self-efficacy than } \\
\text { leaders with less } \\
\text { experience. }\end{array}$ & $\begin{array}{l}\text { Independent variables: } \\
\text {-New Vs Return } \\
\text {-Number of trips led } \\
\text { Dependent variables: } \\
\text { L2, L3, L7\#1, L7\#2 }\end{array}$ & $\begin{array}{l}\text { Fisher's Exact } \\
\text { Test }\end{array}$ \\
\hline $\begin{array}{l}\text { R2) Do Adventure West } \\
\text { Virginia leaders demonstrate } \\
\text { a transference of leadership } \\
\text { skills to areas outside of } \\
\text { AWV across levels of } \\
\text { experience with the } \\
\text { program? }\end{array}$ & $\begin{array}{l}\mathrm{H} 2 \text { ) Leaders with more } \\
\text { experience leading First- } \\
\text { Year trips will } \\
\text { demonstrate a higher level } \\
\text { of transference of } \\
\text { emotional intelligence and } \\
\text { self-efficacy to life outside } \\
\text { of AWV. }\end{array}$ & $\begin{array}{l}\text { Independent variables: } \\
\text {-During FYT trips Vs. } \\
\text { Outside } \\
\text { Grouping } \\
\text { (Stratification } \\
\text { variable): } \\
\text {-New Vs Return } \\
\text {-Number of Trips Led } \\
\text { Dependent variables: } \\
\text { L2, L4, L6, L7\#1, } \\
\text { L7\#2 }\end{array}$ & $\begin{array}{l}\text { Fisher's Exact } \\
\text { Test } \\
\text { Cochran- } \\
\text { Mantel- } \\
\text { Haenszel Test } \\
\text { Kappa Test of } \\
\text { Agreement } \\
\text { Bowker's Test } \\
\text { of Symmetry of } \\
\text { Disagreement }\end{array}$ \\
\hline $\begin{array}{l}\text { R3) Does the level of } \\
\text { involvement across other } \\
\text { Adventure West Virginia } \\
\text { program areas impact } \\
\text { leaders' ability to transfer } \\
\text { leadership skills to life } \\
\text { outside of AWV? }\end{array}$ & $\begin{array}{l}\text { H3) Leaders that hold } \\
\text { additional positions within } \\
\text { AWV will demonstrate a } \\
\text { higher level of } \\
\text { transference of emotional } \\
\text { intelligence and self- } \\
\text { efficacy to other areas of } \\
\text { life than those that only } \\
\text { lead First Year Trips. }\end{array}$ & $\begin{array}{l}\text { Independent variables: } \\
\text {-Just leader or } \\
\text { additional positions } \\
\text { Dependent variables: } \\
\text { L3, L4, L6, L7\#1, } \\
\text { L7\#2 }\end{array}$ & $\begin{array}{l}\text { Fisher's Exact } \\
\text { Test, } \\
\text { Cochran- } \\
\text { Mantel- } \\
\text { Haenszel Test } \\
\text { Kappa Test of } \\
\text { Agreement } \\
\text { Bowker's Test } \\
\text { of Symmetry of } \\
\text { Disagreement }\end{array}$ \\
\hline
\end{tabular}




\section{Chapter 4 \\ Results}

This chapter presents the research study results and covers study response rates, student leader demographic profile, descriptive statistics for key leadership variables, and statistical tests for study research questions. Results are summarized for each research question specified in the introduction. Each section follows the basic outline of restating the research objective and outlining the results found. Each section includes appropriate tables related to the given objective and report the statistical analyses associated with the section.

\section{Response Rate}

The Qualtrics Survey was sent out to all student leaders that had been active, leading atleast one trip, over the summer seasons of 2017, 2018, and 2019. The survey was anonymous and voluntary, and while 99 leaders were asked to participate, only 34 leaders responded. Potential lack of incentive may have affected the response rate leading to a response rate of $34 \%$. Due to some technical challenges when the survey was administered, some of the 34 responses were found to be incomplete. Five respondents either closed the survey or were not shown the leadership questions after answering their demographic questions. This resulted in a total response number of $N=29$, and a final response rate of 29\%. Question L5, which asks participants to rank how impactful leading for AWV was for their growth among eight different leaderships skills, was not marked as required and only received 12 responses, leading to that question being removed from overall result analysis. Response rate results are shown in Table 3 . 
Table 3. Response Rate for Qualtrics Survey

\begin{tabular}{lcc}
\hline \hline & $\underline{\text { Survey Responses }}$ & $\underline{\text { Response Rate }}$ \\
\hline Total Surveys Sent: & 99 & \\
Total Returned: & 34 & $34 \%$ \\
Total Used in Analysis*: & $29 *$ & $29 \%$ \\
\hline
\end{tabular}

*Five respondents were not included in analysis due to incomplete surveys.

\section{Student Leader Demographics}

Study respondents were asked to report on multiple demographic items. In all, seven specific questions were asked relating to respondent demographics (Table 4) or respondent leadership experience (Table 5).

\section{$\underline{\text { Class Year }}$}

With the understanding that to be a FYT leader, one must have at least completed their first year at WVU, responses included 9 sophomores (31.03\%), 8 juniors (27.59\%), 7 seniors (24.14\%), and 5 students that were no longer in school (17.24\%). While this response does not indicate experience level within the AWV program, it does provide insight to ages of the sample population.

Ethnicity

Overwhelmingly, a majority of students associated themselves as being White $(n=28$, 96.55\%). One student chose not to answer.

\section{Gender Identity}

Given 7 options for identifying with gender, a majority of respondents identified as either female $(n=16,55.17 \%)$ or male $(n=12,41.38 \%)$. One respondent identified as genderqueer or gender non-conforming $(n=1,3.45 \%)$. 


\section{$\underline{\text { Financial Aid }}$}

Finally, to gain additional insight on student demographics and financial background, student leaders were asked to report on if they received any financial aid from the university. Fifteen leaders reported that they did receive financial aid from WVU (51.72\%) while the remaining 14 reported that they did not $(48.28 \%)$.

Table 4. Student Leader Demographics

\begin{tabular}{lcc}
\hline \hline Class Year $(N=29)$ & Frequency $(n)$ & Percent of Total \\
\hline Sophomore & 9 & 31.03 \\
Junior & 8 & 27.59 \\
Senior & 7 & 24.14 \\
No Longer in School & 5 & 17.24 \\
Ethnicity* $(N=29)$ & & \\
White & 28 & 96.55 \\
Prefer not to answer & 1 & 3.45 \\
Gender Identity* $(N=29)$ & & \\
Female & 16 & 55.17 \\
Male & 12 & 41.38 \\
Genderqueer or Gender Non-conforming & 15 & 3.45 \\
Financial Aid $(N=29)$ & & 51.72 \\
Yes & 15.28 \\
No & & \\
\hline
\end{tabular}

* Demographic questions that provided alternative answers that received no responses and were removed from table 


\section{$\underline{\text { First Year of Leading FYTs }}$}

To differentiate various experience levels, student leaders were asked to report on the year that they first led an FYT. Leaders answered $2015(\mathrm{n}=1,3.45 \%), 2016(n=3,10.35 \%)$, $2017(n=3,10.35 \%), 2018(n=10,34.48 \%), 2019(n=12,41.38 \%)$. In addition, leaders were categorized by New Leader (NL) or Return Leader (RL) with NL consisting of only leaders that led during the 2019 season $(n=12,41.38 \%)$ and RL consisting of leaders that have led two or more seasons of FYTs $(n=17,58.62 \%)$.

\section{Number of FYTs Led}

The survey also asked respondents to report how many FYT trips they have led. The answers were organized into five categories: 1-2 trips $(n=2,6.90 \%), 3-5$ trips $(n=13,44.83 \%)$, 6-10 trips $(n=6,20.69 \%), 11-15$ trips $(n=6,20.69 \%), 16$ or more trips $(n=2,6.90 \%)$.

\section{Position within AWV}

To help examine levels of experience across different dimensions of FYT leaders, respondents were asked to report if they worked in any other capacity for the AWV program. Student leaders whose only role within AWV was leading FYT trips consisted of 16 students ( $n$ $=16,55.17 \%)$. Student leaders that led FYTs and held other positions within AWV consisted of 13 students $(n=13,44.83 \%)$. Specifically, other AWV areas such as the Program Support Staff $(n=7,24.14 \%)$, Climbing Site Manager $(n=3,10.34 \%)$, or Outdoor Education Center $(n=4$, $13.79 \%$ ). With the assumption that all respondents were FYT leaders in some capacity, they were given the option to select subcategories of their leadership roles. These include just frontcountry ( $n=12,41.38 \%)$, just backcountry $(n=7,24.14 \%)$, or both $(n=10,34.45 \%)$. These responses allow for the creation of the two subgroups: Just Leader (Frontcountry or 
backcountry; L) or Leader and More (Frontcountry or backcountry and at least one other program area; $\mathrm{L}+$ ).

Table 5. Respondent Leadership Experience

Frequency $(n) \quad$ Percent of Total (\%)

First Year Leading FYTs $(N=29)$

2015

1

3.45

2016

3

10.35

2017

3

10.35

2018

10

34.48

2019

12

41.38

New Leader versus Return Leader* $(N=29)$

New Leader (NL)

Return Leader (RL)

Number of FYTs Led** $(N=29)$

1-2

3-5

6-10

11-15

$16+$

2

6.90

Position with Adventure West Virginia

Leader Type $(\mathrm{N}=29)$

Frontcountry

12

41.38

Backcountry

7

24.14

Both

10

34.48

Other AWV Positions

Program Support Staff 
Climbing Site Management

Just Leader or More* $(\mathrm{N}=29)$

Just FYT Leader

FYT Leader + Other Positions

13

* New groupings based on demographic questions

** FYTs (First Year Trips) - AWV's Outdoor Orientation Program

\section{Leadership Questions - Descriptive Results}

Study respondents were also asked to rate different aspects or skill levels of several leadership constructs. Questions were asked relating to these constructs, with all being specified below.

\section{L1: Recommendation of participation to other students}

Leaders were asked on a 7-point Likert-type scale anchored from $1=$ strongly disagree to 7 = strongly agree the following statements: I would recommend participating in a FYT to an incoming freshman and I would recommend applying for a FYT leader position to other students. Respondents strongly agreed that they would recommend participating in an FYT to an incoming freshman $(n=25,86.21 \%)$, while a smaller amount strongly agreed that they would recommend applying for the FYT leader position $(n=20,68.97 \%)$. All respondents said they agreed with the above statements.

\section{L2: Leading FYTs impact on leadership ability}

Students were asked to report on a 7-point Likert-type scale anchored from $1=$ strongly disagree to 7 = strongly agree their level of agreement that leading FYTs has had a tangible, 
positive impact on their leadership ability. A percentage of 96.55 of student leaders strongly agreed or agreed that leading FYTs had a positive impact on their leadership ability $(n=28)$. One leader responded that they strongly disagreed that FYTs had a positive impact on their leadership ability $(n=1,3.45 \%)$.

\section{L3: FYT leadership skills compared to other WVU students}

Students were asked to rate their leadership skills compared to other WVU students on a 7-point Likert-type scale anchored from $1=$ Far below average to $7=$ far above average. $37.93 \%$ of student leaders ranked their leadership skills far above $(n=11)$ and $55.17 \%$ as moderately above average $(n=16)$ when compared to other WVU students. Two leaders responded that they skills were comparable (average) compared to other WVU students (6.90\%).

\section{L4: Transference of leader abilities from FYTs outside of an AWV setting}

In order to analyze and compare certain leadership skills that FYT leaders are trained in, respondents were asked to rank the transference among eight of those skills on a 7-point Likerttype scale anchored from $1=$ strongly disagree to $7=$ strongly agree. All but three leaders indicated that their training and trip experience has allowed them to use all eight skills outside of a trip leader context. Skills that were more easily used outside of that context included Giving and Receiving Feedback $(\bar{x}=6.72)$, Judgement and Decision Making $(\bar{x}=6.55)$, and Relationship and Community Building $(\bar{x}=6.55)$. Following skills included Risk Management $(\bar{x}=6.41)$, Situational Leadership $(\bar{x}=6.28)$, Managing Conflict $(\bar{x}=6.82)$, Wellness and SelfCare $(\bar{x}=5.93)$, and Bystander Intervention $(\bar{x}=6.00)$.

\section{L5: Ranking how impactful leading for AWV has been on certain skill development}

This question was removed from the data analysis due the question not being required in the survey leading to a low response rate. Student leaders were asked to rank eight categories 
from 1 = most impactful to 8 = least impactful based on how impactful leading for AWV had on those categories' growth. Examining the responses from the twelve $(n=12)$ leaders that did answer this question, the descriptive statistics are as follows in descending order from most impactful to least impactful: Giving and Receiving Feedback $(\bar{x}=2.00)$, Relationship and Community Building $(\bar{x}=2.83)$, Situational Leadership $(\bar{x}=3.76)$, Judgement and Decision Making $(\bar{x}=3.75)$, Managing Conflict $(\bar{x}=5.42)$, Wellness and Self-Care $(\bar{x}=5.42)$, Risk Management $(\bar{x}=5.42)$, and Bystander Intervention $(\bar{x}=7.50)$.

\section{L6: Usefulness of leadership skills in settings outside of AWV}

Respondents were asked to rate the usefulness on a scale of seven of their leadership skills to areas outside of AWV on a 7-point Likert-type scale anchored from $1=$ strongly disagree to $7=$ strongly agree. These areas included On the WVU campus $(\bar{x}=6.24)$, In the Community outside of WVU $(\bar{x}=6.24)$, Within student groups $(\bar{x}=6.24)$, In the workplace $(\bar{x}=$ 6.17), With friends/roommates $(\bar{x}=5.97)$, With family members $(\bar{x}=5.72)$.

\section{L7: Transference of emotional intelligence and self-efficacy from FYTs to other areas of life}

This question was broken into two sub questions in order to compare leadership skills: 1) while leading FYT trips and 2) while not leading FYT trips. The specific skills that attempt to measure emotional intelligence are 1) understand my own emotions, 2) read people and their emotions, 3) manage my emotions effectively, and 4) manage other's emotions effectively. The specific skills that attempt to measure self-efficacy include 5) achieve goals that I set for myself, 6) set long-term goals and review my progress regularly. A formal layout of these skills and their relationship to EI and SE can be found in Table 8. Students were asked to report their ability to use these specific skills in two different settings on a 3-point Likert-type scale anchored from $1=$ Not true, 2 = Somewhat true, and 3 = very true. 
Descriptive statistics for L7\#1 include the following fields: While leading FYTs, I am able to... understand my own emotions $(\bar{x}=2.66)$, read people and their emotions $(\bar{x}=2.69)$, manage my emotions effectively $(\bar{x}=2.86)$, and manage other's emotions effectively $(\bar{x}=2.86)$, achieve goals that I set for myself $(\bar{x}=2.69)$, set long-term goals and review my progress regularly $(\bar{x}=2.79)$. Descriptive statistics for L7\#2 include the following fields: Outside of leading FYTs, I am able to... understand my own emotions $(\bar{x}=2.62)$, read people and their emotions $(\bar{x}=2.45)$, manage my emotions effectively $(\bar{x}=2.45)$, and manage other's emotions effectively $(\bar{x}=2.10)$, achieve goals that I set for myself $(\bar{x}=2.52)$, set long-term goals and review my progress regularly $(\bar{x}=2.34)$. Thorough analyses of these results are explained below.

\section{Data Analysis}

\section{Research Question 1}

R1: Does leading outdoor trips for Adventure West Virginia improve leaders's self-perceived emotional intelligence and self-efficacy across levels of experience with the program?

Null-Hypothesis 1: There is no significant difference between leaders of varying experience levels when measuring leadership skills.

\section{Variables}

In order to compare and analyze leadership skills across levels of experience among FYT leaders, different groupings needed to be created. Two types of ratio data could be used to measure that experience: 1) the number of seasons a leader has led, and 2) the number of trips a leader has led. Each of these identifiers were tested in order to see if one provided more meaningful results. 
Focusing on the number of seasons led as a variable, student leader experience levels were separated into two groups based on growth over time as new leaders (NL) were categorized as having led during the 2019 season only and Return Leaders (RL) were categorized as having led two or more seasons during their time with AWV. Focusing on number of trips led as a variable, student leader experience levels were separated into five groups based on actual amount of time in the field (1-2 trips, 3-5 trips, 6-10 trips, 11-15 trips, 16+ trips). The y-variable included responses from questions L2, L3, and L7. For analyses of questions L2 and L3, EI and SE were combined into the single category of leadership skills. In the analysis of L7, EI and SE were separated but not compared inside and outside of trip leading.

\section{L2 Analysis: Leading FYTs impact on leadership ability}

Due to a small sample size of $\mathrm{N}=29$, Fisher's Exact test of independence was used to examine if student trip leaders felt thought that leading FYTs had an impact on their leadership ability via contingency tables in JMP. The results of this analysis when controlling for New Leaders versus Return Leaders or Number of Trips are shown in Table 6. When testing the contingency table of New versus Return leaders, the resulting $p$-value was 1 , leading researchers to fail to reject the null hypothesis of equal proportions at the $\alpha=0.05$ level. This result is not surprising given the lack of variation in leaders responses to items under Question L2. When testing the contingency table of Number of Trips, the resulting $p$-value was 0.3410 , leading researchers to again fail to reject the null hypothesis of equal proportions at the $\alpha=0.05$ level. 
Table 6. Group Difference of FYT Impact on Student Leader Leadership Ability

\begin{tabular}{ccccc}
\hline \hline & $\underline{N}$ & $\underline{D F}$ & $\underline{R \text { Square }(U)}$ & Fisher's Exact Test \\
\hline New Leader versus Return Leader & 29 & & & \\
Number of Trips Led & & 2 & .0492 & 1.000 \\
& 29 & 8 & .3410 & .341 \\
\hline
\end{tabular}

\section{L3 Analysis: Self-perceived FYT leadership skills compared to other WVU students}

Fisher's Exact testing independence of leadership skills and leadership experience (New Leaders versus Return Leaders and Number of Trips Led) variables was analyzed using contingency tables in JMP. The results of these analyses are shown in Table 7. When testing the contingency table of New versus Return leaders, the resulting $p$-value was 0.0107 , leading researchers to reject the null hypothesis of equal proportions at the $\alpha=0.05$ level. Specifically, compared to other WVU students, a larger proportion of return leaders (52.9\%) reported the strongest confidence in their leadership ability (level 7), while new leaders were less optimistic $(8.3 \%)$, (see Figure 1). Benjamini-Hochberg procedure was used to remain conservative with the results and correct for any family-wise errors with a false discovery rate of 0.3 , and the resulting $p$-value was no longer significant, indicating a need for a larger sample size (Benjamini \& Hochberg, 1995). When testing the contingency table of Number of Trips, the resulting $p$-value was 0.4698 , leading researchers fail to reject the null hypothesis of independence. In conclusion, varying levels of experience did not reflect increased confidence of leadership ability compared to other WVU students. 
Table 7. Group Difference of Self-perceived Leadership Ability Compared to Other WVU Students

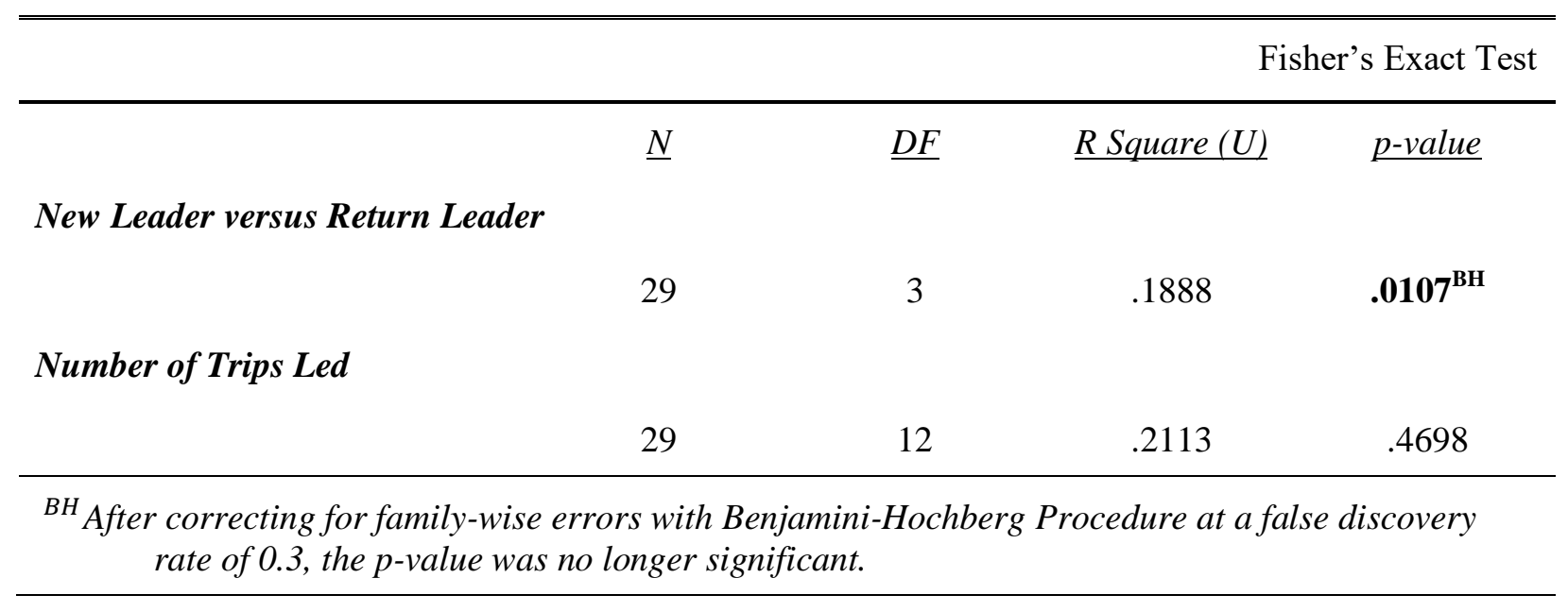

Figure 1. New versus Return Leader Confidence in Skills Compared to Other WVU Students

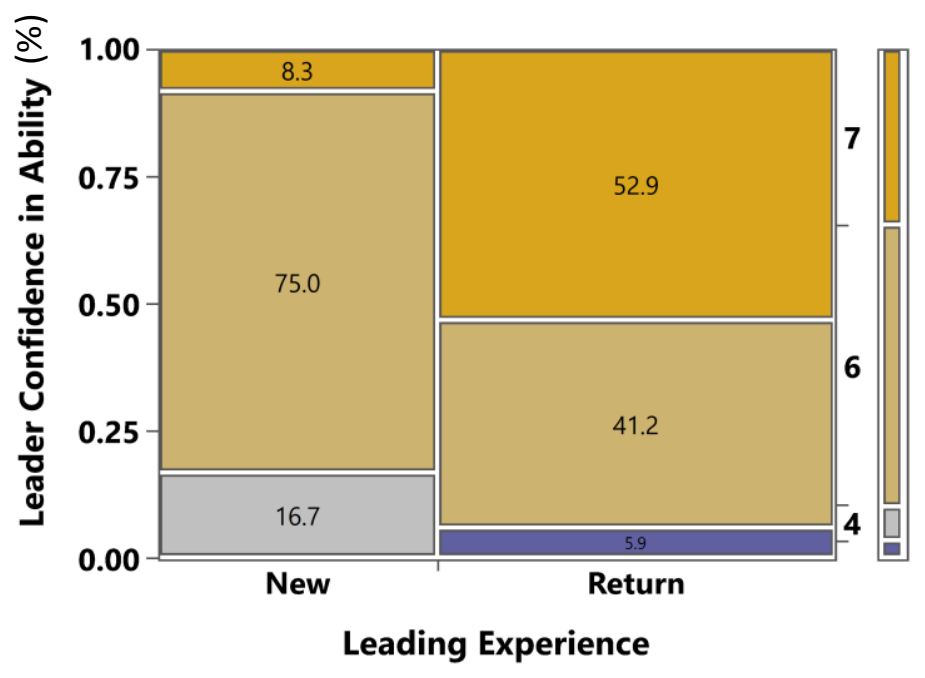

L7 Analysis: Difference in skill levels of emotional intelligence and self-efficacy across experience levels

Fisher's Exact test of independence was performed on the above variables as contingency tables in JMP due to a small sample size of $N=29$. The results of this analysis with two independent variables, New Leaders versus Return Leaders and Number of Trips are shown in Table 8 . When only examining responses across experience levels, there was no statistical 
significance difference between less experienced and more experienced leaders; leading researchers to fail to reject the null hypothesis of equal proportions at the $\alpha=0.05$ level. See Table 8 below for full results.

Table 8. Group Difference of Emotional Intelligence and Self-Efficacy Skills Within and Outside of FYTs

\begin{tabular}{|c|c|c|c|c|c|}
\hline \multicolumn{4}{|l|}{$N=29$} & \multicolumn{2}{|c|}{ Fisher's Exact Test } \\
\hline$\underline{\text { Situation }}$ & $\underline{\text { Skill Area }}$ & $\underline{\text { Response Characteristic }}$ & $\underline{D F}$ & $\underline{R}$ Square $(U)$ & p-value \\
\hline \multicolumn{6}{|c|}{ Independent Variable: New Leader vs Return Leader } \\
\hline \multirow{6}{*}{$\begin{array}{l}\text { During } \\
\text { FYT }\end{array}$} & \multirow[t]{4}{*}{ EI } & Understand my emotions & 2 & .0314 & .8188 \\
\hline & & Read people and their emotions & 1 & .0014 & 1.000 \\
\hline & & Manage my emotions effectively & 1 & .0931 & .2785 \\
\hline & & Manage other's emotions effectively & 2 & .0635 & .3283 \\
\hline & \multirow[t]{2}{*}{$\mathrm{SE}$} & Achieve goals that I set for myself & 2 & .1052 & .092 \\
\hline & & $\begin{array}{l}\text { Set long-term goals and review my progress } \\
\text { regularly }\end{array}$ & 1 & .0078 & .6693 \\
\hline \multirow{6}{*}{$\frac{\text { Outside of }}{\text { FYTs }}$} & \multirow[t]{4}{*}{ EI } & Understand my emotions & 1 & .0048 & .7167 \\
\hline & & Read people and their emotions & 1 & .0021 & 1.000 \\
\hline & & Manage my emotions effectively & 2 & .0414 & .5614 \\
\hline & & Manage other's emotions effectively & 2 & .0016 & 1.000 \\
\hline & \multirow[t]{2}{*}{$\mathrm{SE}$} & Achieve goals that I set for myself & 2 & .0235 & 1.000 \\
\hline & & $\begin{array}{l}\text { Set long-term goals and review my progress } \\
\text { regularly }\end{array}$ & 2 & .0868 & .1101 \\
\hline \multicolumn{6}{|c|}{ Independent Variable: Number of Trips Led } \\
\hline \multirow{5}{*}{$\begin{array}{l}\text { During } \\
\text { FYT }\end{array}$} & \multirow[t]{4}{*}{ EI } & Understand my emotions & 8 & .200 & .5058 \\
\hline & & Read people and their emotions & 4 & .0775 & .8297 \\
\hline & & Manage my emotions effectively & 4 & .1640 & .8818 \\
\hline & & Manage other's emotions effectively & 8 & .1955 & .3825 \\
\hline & SE & Achieve goals that I set for myself & 4 & .1053 & .0920 \\
\hline
\end{tabular}




\begin{tabular}{|c|c|c|c|c|c|}
\hline & & $\begin{array}{l}\text { Set long-term goals and review my progress } \\
\text { regularly }\end{array}$ & 4 & .1807 & .4874 \\
\hline \multirow{6}{*}{$\frac{\text { Outside of }}{\text { FYTs }}$} & EI & Understand my emotions & 4 & .1053 & .6206 \\
\hline & & Read people and their emotions & 4 & .1453 & .3471 \\
\hline & & Manage my emotions effectively & 8 & .1287 & .7768 \\
\hline & & Manage other's emotions effectively & 8 & .1535 & .5445 \\
\hline & SE & Achieve goals that I set for myself & 8 & .1952 & .4631 \\
\hline & & $\begin{array}{l}\text { Set long-term goals and review my progress } \\
\text { regularly }\end{array}$ & 8 & .1669 & .6746 \\
\hline
\end{tabular}

EI = Emotional Intelligence as explained in Chapter 2

SE $=$ Self-Efficacy as explained in Chapter 2

\section{Research Question 2}

R2: Do Adventure West Virginia leaders demonstrate a transference of leadership skills to areas outside of AWV across levels of experience with the program?

Null-Hypothesis 2: There is no significant difference between leaders of varying experience levels (amount of time leading) when measuring transference of emotional intelligence and selfefficacy.

\section{Variables}

Expanding on Research Question 1, researchers wanted to examine how well FYT leaders are able to transfer their leadership skills to other areas of life. In order to so, statistical analyses were done on survey questions addressing that transference while continuing to test both grouping variables of New versus Return Leader and Number of Trips. Following statistical analyses, researchers decided to only continue testing for the independent variable of New versus 
Return Leader due to it having a smaller number of groups (of two instead of five) for Number of Trips. The questions that were analyzed included L4, L6, and L7.

\section{L4 Analysis: Expansion of leader abilities from FYTs outside of an AWV setting}

Fisher's Exact test of independence was performed between leadership experience (New versus Return Leaders) and expansion of leaders' ability to use certain, trained skills in settings outside of AWV. Results are summarized in Table 9. When testing the contingency table of New versus Return leaders, the skill Wellness and Self-Care yielded a significant resulting $p$-value of .0497 ; leading researchers to reject the null hypothesis of equal proportions at the $\alpha=0.05$ level. Specifically, return leaders were more confident in their ability to expand skills related to wellness and self-care to settings outside of AWV (41.2\%) compared to new leaders (16.7\%). These differences are shown in Figure 2. Benjamini-Hochberg test was used to correct for any family-wise errors with a false discovery rate of 0.3 , and the resulting $p$-value was no longer significant; leading to researchers failing to reject the null hypothesis. 
Table 9. Group Difference of the Expansion of Skills Outside of a Trip Leading Context

\begin{tabular}{lcccc}
\hline \hline New Leader versus Return Leader $(N=29)$ & & \multicolumn{2}{c}{ Fisher's Exact Test } \\
\hline$\underline{\text { Skill }}$ & $\underline{\text { Skill Area }}$ & $\underline{D F}$ & $\underline{R \text { Square }(U)}$ & $\underline{p \text {-value }}$ \\
\hline Situational Leadership & Emotional Intelligence & 2 & .0758 & .361 \\
Judgement and Decision-Making & Self-Efficacy & 1 & .0278 & .4515 \\
Giving and Receiving Feedback & Emotional Intelligence & 2 & .0618 & .6347 \\
Risk Management & Self-Efficacy & 1 & .0159 & .4713 \\
Bystander Intervention & Emotional Intelligence & 3 & .0520 & .2912 \\
Wellness and Self-Care & Self-Efficacy & 3 & .1135 & $.0497^{B H}$ \\
Relationship and Community Building & Emotional Intelligence & 2 & .0023 & 1.000 \\
Managing Conflict & Emotional Intelligence & 2 & .0040 & .8854 \\
\hline
\end{tabular}

${ }^{B H}$ After correcting for family-wise errors with Benjamini-Hochberg Procedure at a false discovery rate of 0.3 , the p-value was no longer significant.

Figure 2. New vs. Return Leader Confidence in Ability to Use Wellness and Self Care Skills

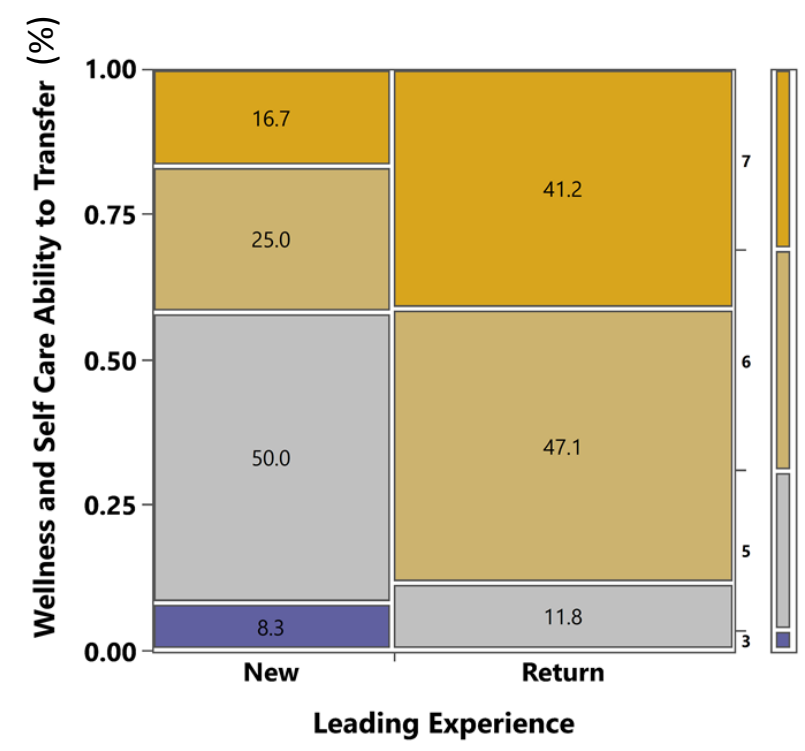




\section{L6 Analysis: Usefulness of leadership skills in settings outside of AWV}

Fisher's Exact test of independence was performed on the above variables as contingency tables in JMP due to a small sample size of $N=29$. The results of this analysis when controlling for New Leaders versus Return Leaders are shown in Table 10. When examining responses across experience levels, there was no statistical significance difference between new and return leaders and researcher failed to reject the null hypothesis of equal proportions at the $\alpha=0.05$ level. See Table 10 below for full results.

Table 10. Group Differences of Usefulness of AWV Taught Leadership Skills to Other Settings

\begin{tabular}{lccc}
\hline \hline New Leader versus Return Leader $(N=29)$ & & Fisher's Exact Test \\
\hline$\underline{\text { Social Environment }}$ & $\underline{D F}$ & $\underline{R \text { Square }(U)}$ & $\underline{p \text {-value }}$ \\
\hline On the WVU Campus & 3 & .0454 & .5875 \\
In the Community Outside Of WVU & 3 & .0927 & .1231 \\
Within Student Groups & 3 & .0750 & .3529 \\
With Friends/Roommates & 4 & .1033 & .147 \\
With Family Members & 4 & .1042 & .1263 \\
In the Workplace & 4 & .0748 & .4558 \\
\hline
\end{tabular}

\section{L7 Analysis: Transference of emotional intelligence and self-efficacy from FYTs to other areas of life}

Question L7 was designed to give researchers the most insight to FYT leaders transference levels of Emotional Intelligence and Self-Efficacy individually. Full results can be found in Table 11. In order to examine if there was a transference of these skills among the entire sample population, categorical, repeated measures $\mathrm{CMH}$ utilized L7\#1 scores (while leading a 
FYT trip), compared to L7\#2 scores (outside of leading a FYT trip) to create a $p$-value. Graph of response rates of total population across both L7s is shown in Figure 6 below.

Results demonstrated that leaders were less confident in their ability to use every skill in settings outside of leading FYTs; however, in three areas, results demonstrated statistically significant dependence between leader experience and level of transference. Skills including reading people and their emotions $(p=.0196)$, managing my emotions effectively $(p=.0027)$, and setting long-term goals and reviewing my progress regularly $(p=.0067)$ were the least transferred to areas outside of FYTs (Table 11).

Table 11. Transference of Emotional Intelligence and Self-Efficacy Skills to Other Areas of Life Transference (During FYTs vs. Outside FYTs) Cochran Mantel Haenszel Test

\begin{tabular}{|c|c|c|c|c|c|}
\hline$\underline{\text { Skill Area }}$ & $\underline{\text { Skill }}$ & $\underline{N}$ & $\underline{D F}$ & $\underline{R \text { Square }(U)}$ & p-value \\
\hline \multirow{4}{*}{$\begin{array}{l}\text { Emotional } \\
\text { Intelligence }\end{array}$} & Understand my emotions & 58 & 2 & .0238 & .763 \\
\hline & Read people and their emotions & 58 & 1 & .0439 & $.0196 *$ \\
\hline & Manage my emotions effectively & 58 & 2 & .1283 & $.0027 *$ \\
\hline & Manage other's emotions effectively & 58 & 2 & .0366 & .0522 \\
\hline \multirow[t]{2}{*}{ Self-Efficacy } & Achieve goals that I set for myself & 58 & 2 & .0225 & .2513 \\
\hline & $\begin{array}{l}\text { Set long-term goals and review my progress } \\
\text { regularly }\end{array}$ & 58 & 2 & .0960 & $.0067 *$ \\
\hline
\end{tabular}

$*$ Denotes significance between groups at the $\alpha=0.05$ level 
iggure 6. Response Counts of Leader Confidence in Ability to Transfer Skills

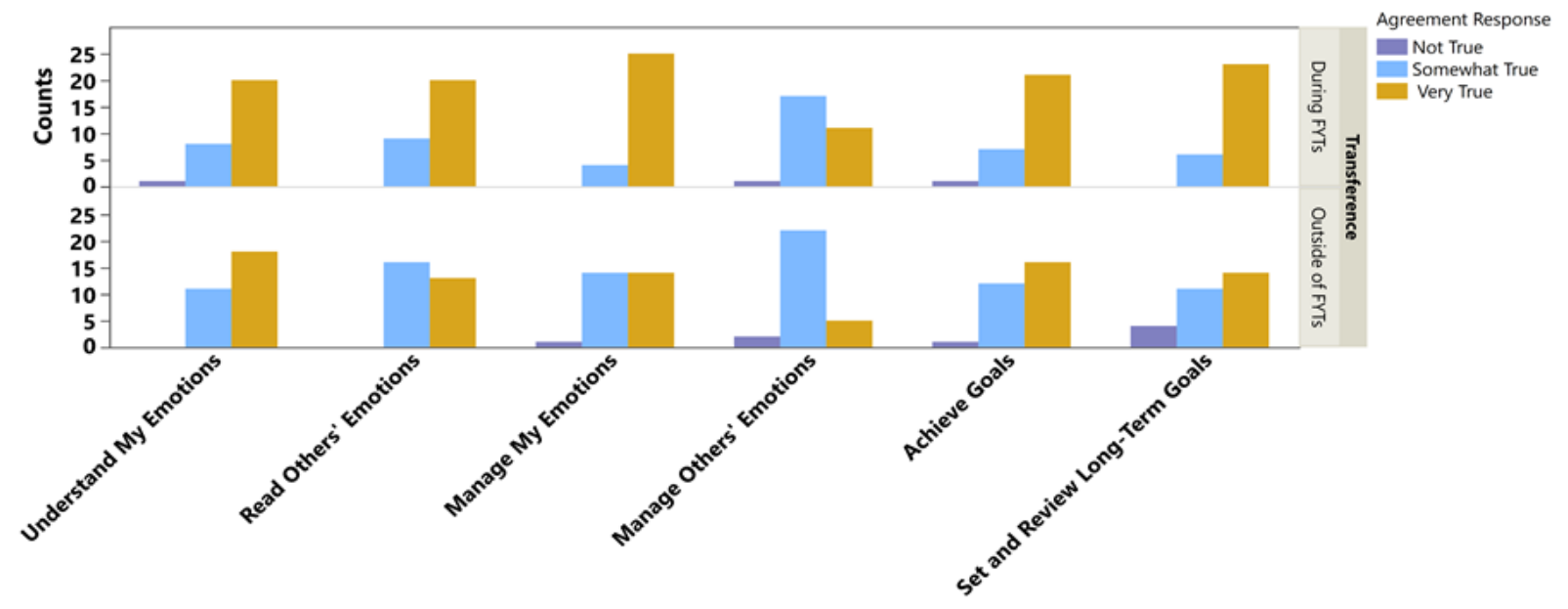


Using the Kappa Agreement Test, overall transference of skills was analyzed regardless of leadership experience level. Three skills were found to have high levels of agreement between during FYT and outside of FYT settings: understand my emotions $(p=.0086)$, read people and their emotions effectively $(p=.0072)$, and manage others' emotions $(p=.0203)$. All three of these skills are related more closely with emotional intelligence and suggest that leaders are transferring sills related to emotional intelligence better than those related to self-efficacy. Results are shown in Table 12.

Table 12. Transference of Emotional Intelligence and Self-Efficacy Skills to Other Areas of Life Measured by Agreement Test (Kappa) and Bowker's Test of Symmetry of Disagreement

\begin{tabular}{|c|c|c|c|c|c|}
\hline \multicolumn{2}{|c|}{ Transference (During FYTs vs. Outside FYTs) } & \multicolumn{2}{|c|}{$\begin{array}{l}\text { Test of Agreement } \\
\text { (Kappa) }\end{array}$} & \multicolumn{2}{|c|}{$\begin{array}{l}\text { Bowker's Test of } \\
\text { Symmetry of Disagreement }\end{array}$} \\
\hline$\underline{\text { Skill Area }}$ & $\underline{\text { Skill }}$ & $\underline{\text { Kappa }}$ & $\underline{\text { Prob }>z}$ & Chi-Square & $\underline{\text { Prob }>C h i S q}$ \\
\hline \multirow{4}{*}{$\begin{array}{l}\text { Emotional } \\
\text { Intelligence }\end{array}$} & Understand my emotions & .4096 & $.0086^{*}$ & 2.2857 & .5153 \\
\hline & Read people and their emotions & .4027 & $.0072 *$ & 5.4444 & $.0196 *$ \\
\hline & Manage my emotions effectively & .1333 & .1365 & 9.3333 & $.0252 *$ \\
\hline & $\begin{array}{l}\text { Manage other's emotions } \\
\text { effectively }\end{array}$ & .2927 & $.0203 *$ & 10 & $.0186^{*}$ \\
\hline \multirow[t]{2}{*}{$\begin{array}{l}\text { Self- } \\
\text { Efficacy }\end{array}$} & $\begin{array}{l}\text { Achieve goals that I set for } \\
\text { myself }\end{array}$ & .1024 & .2558 & 2.2727 & .5178 \\
\hline & $\begin{array}{l}\text { Set long-term goals and review } \\
\text { my progress regularly }\end{array}$ & .1038 & .2104 & 7.6 & .0550 \\
\hline
\end{tabular}

*Denotes significant agreement between During and Outside FYTs for Kappa test, and asymmetry of the specific skill scores During and Outside FYTs at the $\alpha=0.05$ level

In order to gain insight into how leaders transfer each skill, mosaic plots (JMP) were used for comparison. These plots allow researchers to compare leader responses in each setting (during and outside of FYTs) to understand transference trends of the overall sample group. A graph of the transference of entire sample is shown in Figure 6 above. 
Figure 3. Leader Confidence in Ability to Read Others' Emotions

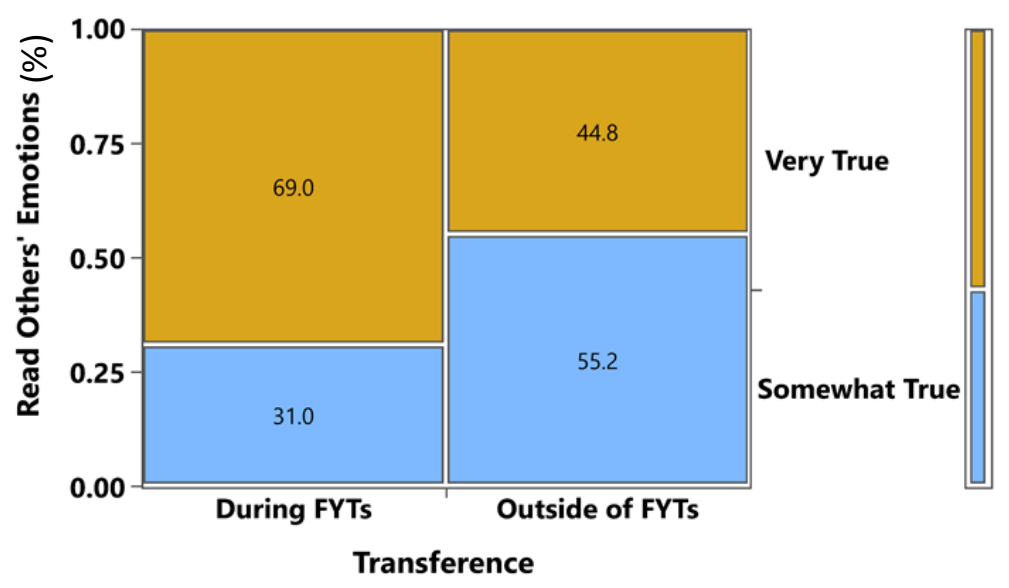

Looking at each of these skills specifically, we found that the majority (69.0\%) of leaders excel in the ability to read other peoples' emotions while they are leading FYTs; however, less than half $(44.8 \%)$ were able to apply that skill in areas outside of leading FYTs (Figure 3).

Figure 4. Leader Confidence in Ability to Manage Their Own Emotions

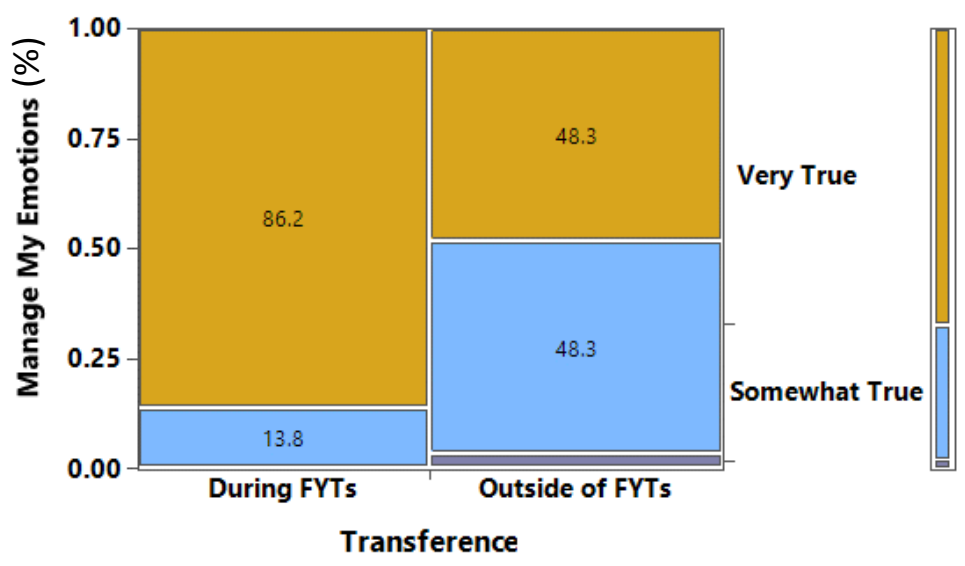

A similar pattern was observed with leader ability to manage their own emotions. The most common answer indicated that leaders are more confident in their ability to manage their own emotions while leading FYTs $(86.2 \%)$ than they are using that same skill in areas outside of leading FYT (48.3\%). This relationship is depicted in Figure 4. 
Figure 5. Leader Confidence in Ability to Set Long Term Goals and Review Them Regularly

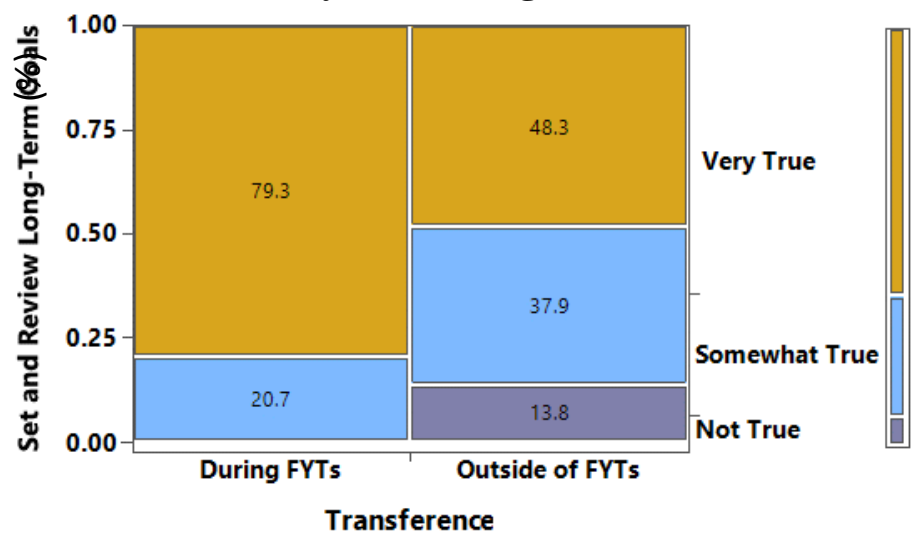

Likewise, leader confidence in ability to set long-term goals and check progress regularly decreased when transferring the skill to other areas of life. $79.3 \%$ of leaders were confident in their ability to use this skill while leading FYTs, but only $48.3 \%$ were confident that they were able to use the same skill in life outside of FYTs. This relationship is depicted in Figure 5.

Further transference of emotional intelligence and self-efficacy skills of the was analyzed controlling for varying levels of experience among leaders: New Leaders and Return Leaders. The comparison between during FYTs and outside of FYTs generated a single $p$-value (row mean score difference in CMH test). For two skills, statistically significant $p$-values were found regarding dependence on grouping variable and transference: Managing my emotions effectively $(p=.002)$ and Setting long-term goals and reviewing my progress regularly $(p=.0067)$. Similar to the results shown in Table 11, leader confidence in these skills was significantly reduced when being transferred to settings outside of AWV. Significant results indicate that return leaders experienced a larger reduction in confidence in ability to use skills in settings outside of FYTs. For all other skills, there were no statistically significant differences between more or less experienced leaders. These values are displayed in Table 13. 
Table 13. Group Difference of Transference of EI and SE Skills to Other Areas of Life

\begin{tabular}{|c|c|c|c|c|}
\hline \multicolumn{3}{|c|}{ Controlling for New Leaders and Return Leaders } & \multicolumn{2}{|c|}{ Cochran-Mantel-Haenszel Test } \\
\hline$\underline{\text { Skill Area }}$ & $\underline{\text { Skill }}$ & CMH Chi-Sq & $\underline{D F}$ & $\frac{\begin{array}{c}p \text {-value } \\
\text { (row score by col. }\end{array}}{\text { probability) }}$ \\
\hline \multirow{4}{*}{$\begin{array}{l}\text { Emotional } \\
\text { Intelligence }\end{array}$} & Understand my emotions & 0.0629 & 1 & .802 \\
\hline & Read people and their emotions & 3.3328 & 1 & .0679 \\
\hline & Manage my emotions effectively & 9.5222 & 1 & $.0020 *$ \\
\hline & Manage other's emotions effectively & 3.0161 & 1 & .0824 \\
\hline \multirow[t]{2}{*}{ Self-Efficacy } & Achieve goals that I set for myself & 1.3527 & 1 & .2448 \\
\hline & $\begin{array}{l}\text { Set long-term goals and review my } \\
\text { progress regularly }\end{array}$ & 7.3403 & 1 & $.0067 *$ \\
\hline
\end{tabular}

*Denotes statistically significant association of EI and SE skills score $(1,2,3)$ and corresponding transference (during FYTs and outside of FYTs), while controlling for New and Return Leader groups.

Utilizing the Kappa Agreement Test, overall transference of skills was analyzed on groups divided by experience level (new and return leaders). Three skills were found to have high levels of agreement between during FYT and outside of FYT settings: understand my emotions $(p=.0063)$, read people and their emotions effectively $(p=.006)$, and manage others' emotions $(p=.0442)$. The group that experienced this significant skill transfer agreement was return leaders. New leaders experienced no significant skill transfer agreement. All three of these skills are related more closely with emotional intelligence and suggest that leaders are transferring sills related to emotional intelligence better than those related to self-efficacy. Results are shown in Table 14. 
Table 14. Transference of Emotional Intelligence and Self-Efficacy Skills to Other Areas of Life Measured by Agreement Test (Kappa) and Bowker's Test of Symmetry of Disagreement

\begin{tabular}{|c|c|c|c|c|c|}
\hline \multicolumn{2}{|c|}{ Transference (During FYTs vs. Outside FYTs) } & \multicolumn{2}{|c|}{$\begin{array}{l}\text { Test of Agreement } \\
\text { (Kappa) }\end{array}$} & \multicolumn{2}{|c|}{$\begin{array}{l}\text { Bowker's Test of } \\
\text { Symmetry of Disagreement }\end{array}$} \\
\hline $\begin{array}{l}\text { Leadership } \\
\text { Experience }\end{array}$ & $\underline{\text { Skill }}$ & $\underline{\text { Kappa }}$ & $\underline{\text { Prob }>z}$ & $\underline{\text { Chi-Square }}$ & $\underline{\text { Prob }>C h i S q}$ \\
\hline \multirow{6}{*}{$\begin{array}{l}\text { New } \\
\text { Leaders }\end{array}$} & Understand my emotions & .25 & .1932 & 0 & 1 \\
\hline & Read people and their emotions & .1111 & .3001 & 2.8 & .4235 \\
\hline & Manage my emotions effectively & .2105 & .2038 & 1.8 & .1797 \\
\hline & $\begin{array}{l}\text { Manage other's emotions } \\
\text { effectively }\end{array}$ & .2615 & .1215 & 4 & .2615 \\
\hline & Achieve goals that I set for myself & -.0286 & .4606 & 0 & 1 \\
\hline & $\begin{array}{l}\text { Set long-term goals and review my } \\
\text { progress regularly }\end{array}$ & .2 & .1362 & 3 & .3916 \\
\hline \multirow{6}{*}{$\begin{array}{l}\text { Return } \\
\text { Leaders }\end{array}$} & Understand my emotions & .5177 & $.0063 *$ & 4 & .2615 \\
\hline & Read people and their emotions & .5405 & $.006 *$ & 4 & $.0455^{*}$ \\
\hline & Manage my emotions effectively & .1314 & .1371 & 7 & $.0082 *$ \\
\hline & $\begin{array}{l}\text { Manage other's emotions } \\
\text { effectively }\end{array}$ & .3108 & $.0442 *$ & 6 & .1116 \\
\hline & Achieve goals that I set for myself & .1959 & .1061 & 5 & .1718 \\
\hline & $\begin{array}{l}\text { Set long-term goals and review my } \\
\text { progress regularly }\end{array}$ & .0671 & .3345 & 5.5 & .1386 \\
\hline
\end{tabular}

*Denotes significant agreement between During and Outside FYTs for Kappa test, and asymmetry of the specific skill scores During and Outside FYTs at the $\alpha=0.05$ level

In order to gain insight into how leaders of different experience levels transfer each skill, mosaic plots were used for comparison. These plots allow researchers to compare each group's transference in order to see if one group showed patterns of higher transference. The patterns shown in these plots are supported by significant agreement values found by the Kappa test of agreement in Table 14. A graph of the transference of entire sample is shown in Figure 6. This section is broken into two sub-sections: emotional intelligence skills and self-efficacy skills. 


\section{Emotional Intelligence}

Figure 7. New vs Return Leader Confidence in Ability to Understand Their Emotions Skill: Understand My Emotions
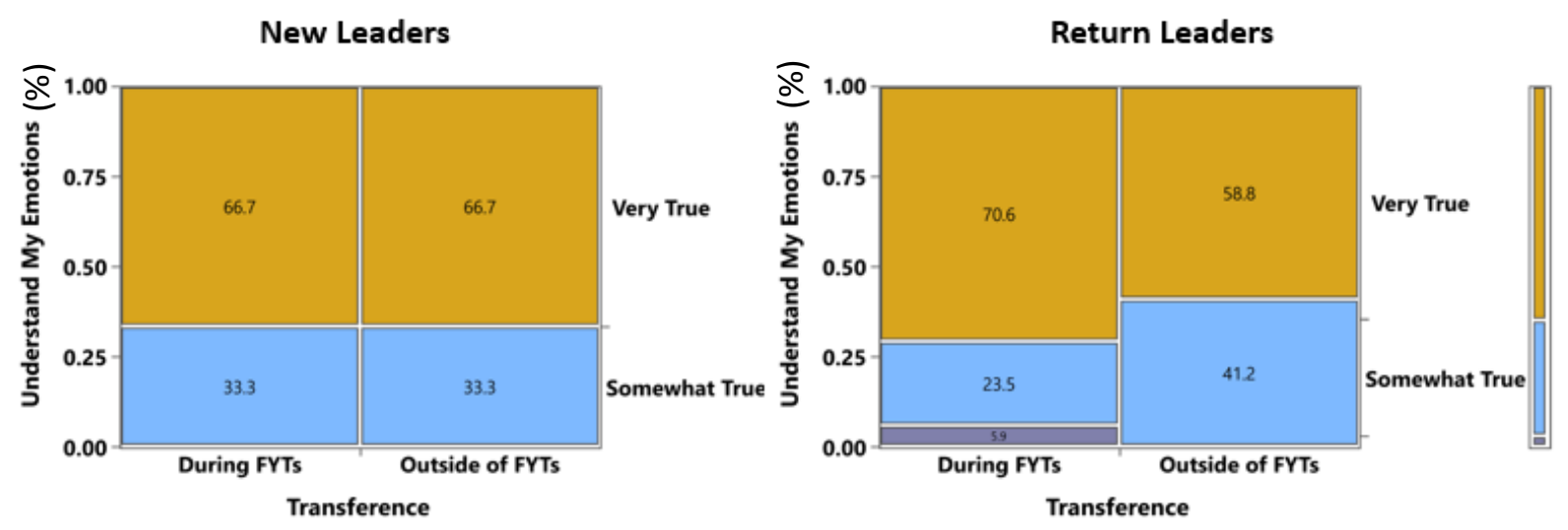

Beginning by examining skills related to Emotional Intelligence, when comparing confidence in leader ability to understand their emotions during and outside of trips, researchers found that new leaders reported no change in confidence levels $(66.7 \%)$. Return leaders were initially more confident that new leaders $(70.6 \%)$ but reported less transference of the skill to areas outside of AWV (58.8\%).

Figure 8. New vs Return Leader Confidence in Ability to Read People and Their Emotions Skill: Read People and Their Emotions
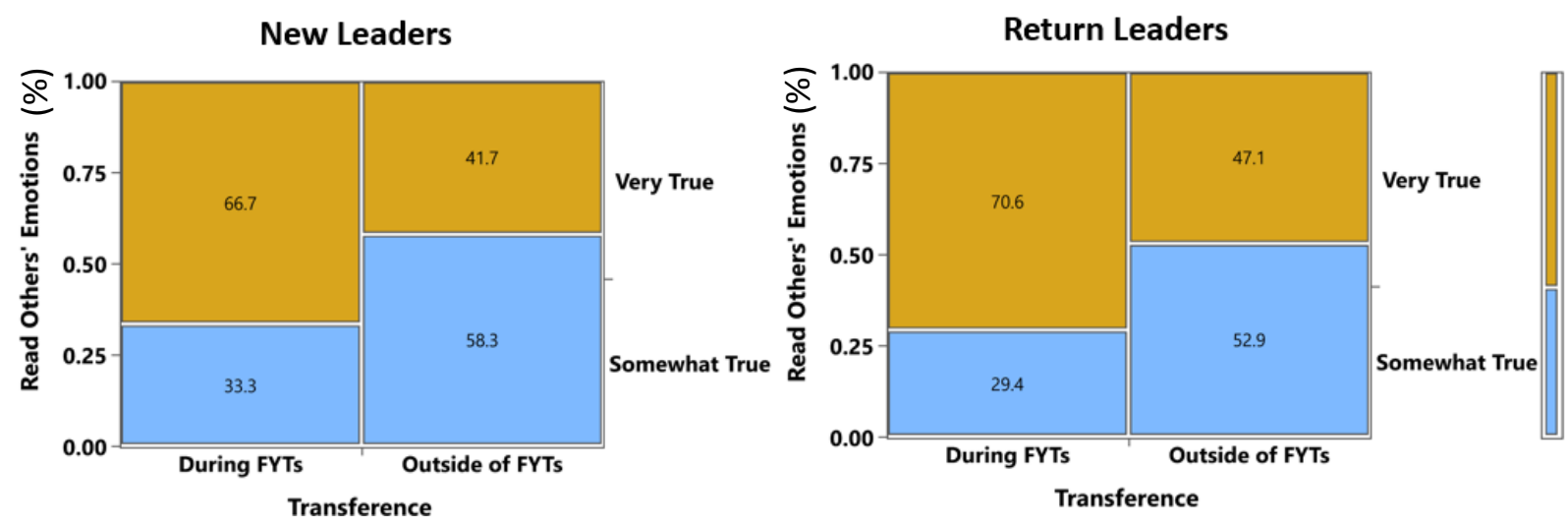

When comparing transference of the ability to read people and their emotions,

researchers found that return leaders reported more confidence both during (70.6\%) and outside 
(47.1\%) of trips compared to new leaders $(66.7 \%, 41.7 \%)$. New leaders' confidence levels dropped $25.0 \%$ while returned leaders levels dropped $23.5 \%$.

Figure 9. New vs Return Leader Confidence in Ability to Manage Their Own Emotions

\section{Skill: Manage My Own Emotions}
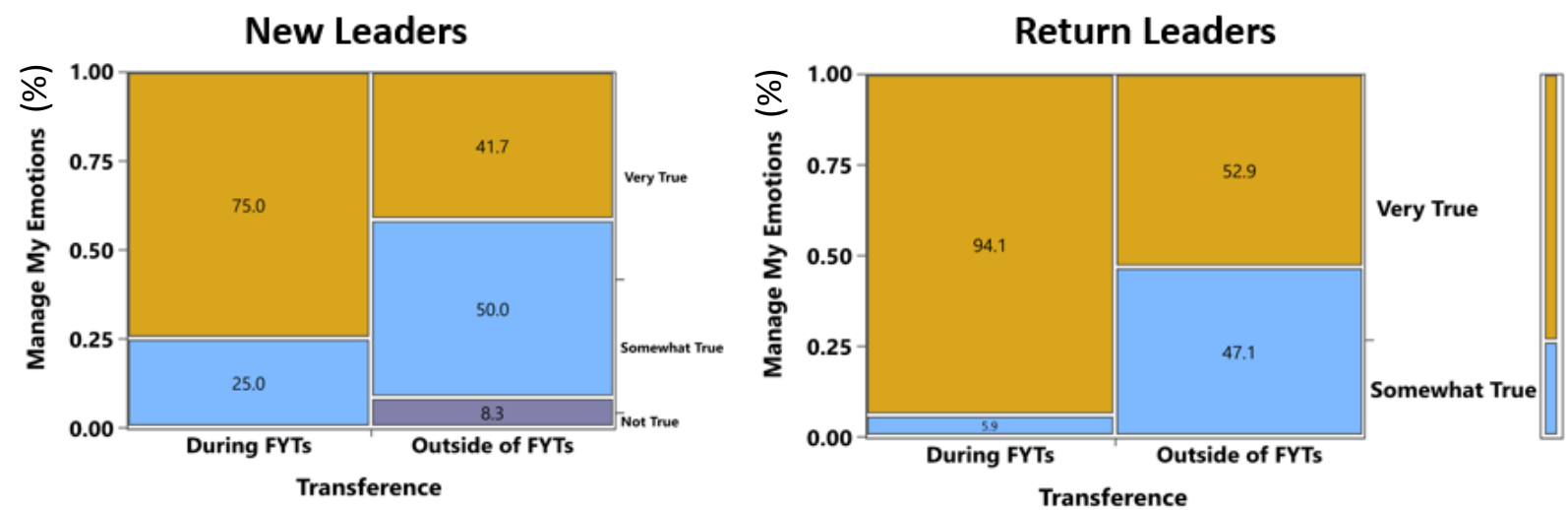

When comparing confidence of leader ability to manage their emotions, researchers

found that return leaders were more confident in their ability to use the skill both during (94.1\%) and outside $(52.9 \%)$ of trips compared to new leaders $(75.0 \%, 41.7 \%)$. New leaders saw a $33.3 \%$ decrease in confidence while return leader saw a $41.2 \%$ decrease.

Figure 10. New vs Return Leader Confidence in Ability to Manage Other's Emotions Effectively

\section{Skill: Manage Others' Emotions Effectively}
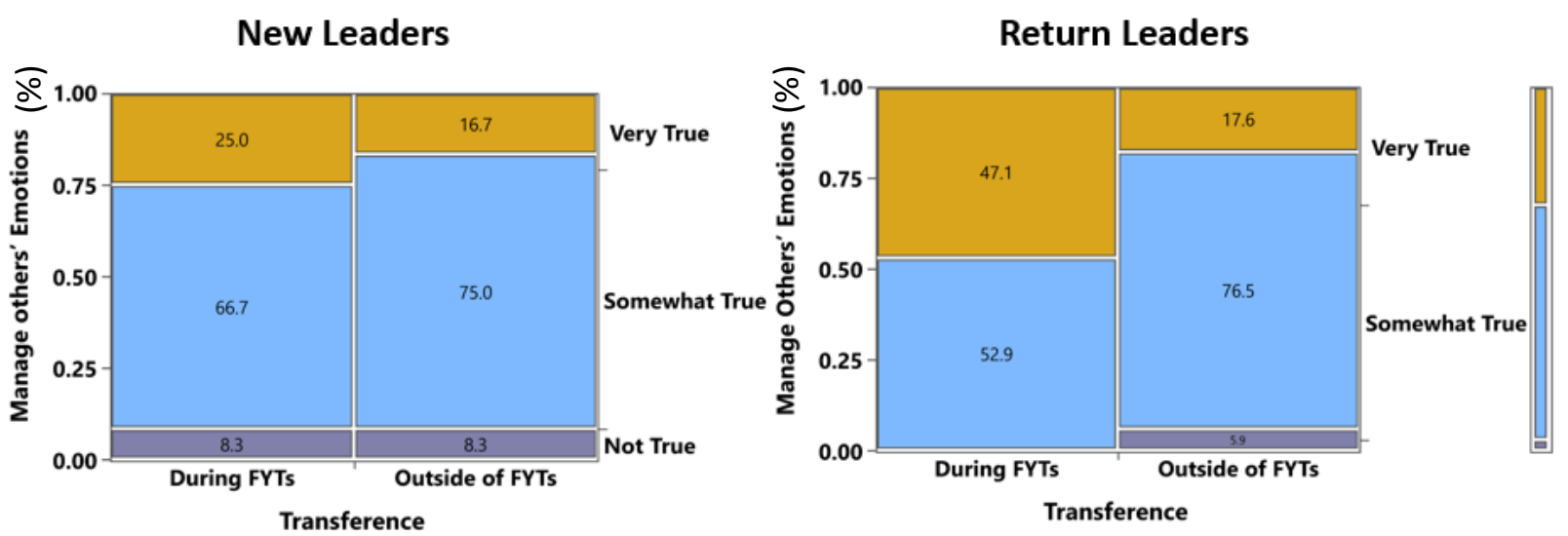
Both new and return leaders reported the lowest confidence levels when asked about their ability to manage others' emotions effectively. Return leaders, although reporting more confidence in their ability to use the skill during trips $(47.1 \%)$, reported a larger reduction of skill ability $(29.5 \%$ reduction) when not leading trips $(17.6 \%)$. New leaders reported low confidence and transference of the skill both during and outside of trips $(25.0 \%, 16.7 \%)$.

\section{Self-Efficacy}

Figure 11. New vs Return Leader Confidence in Ability to Achieve Goals They Set for Themselves
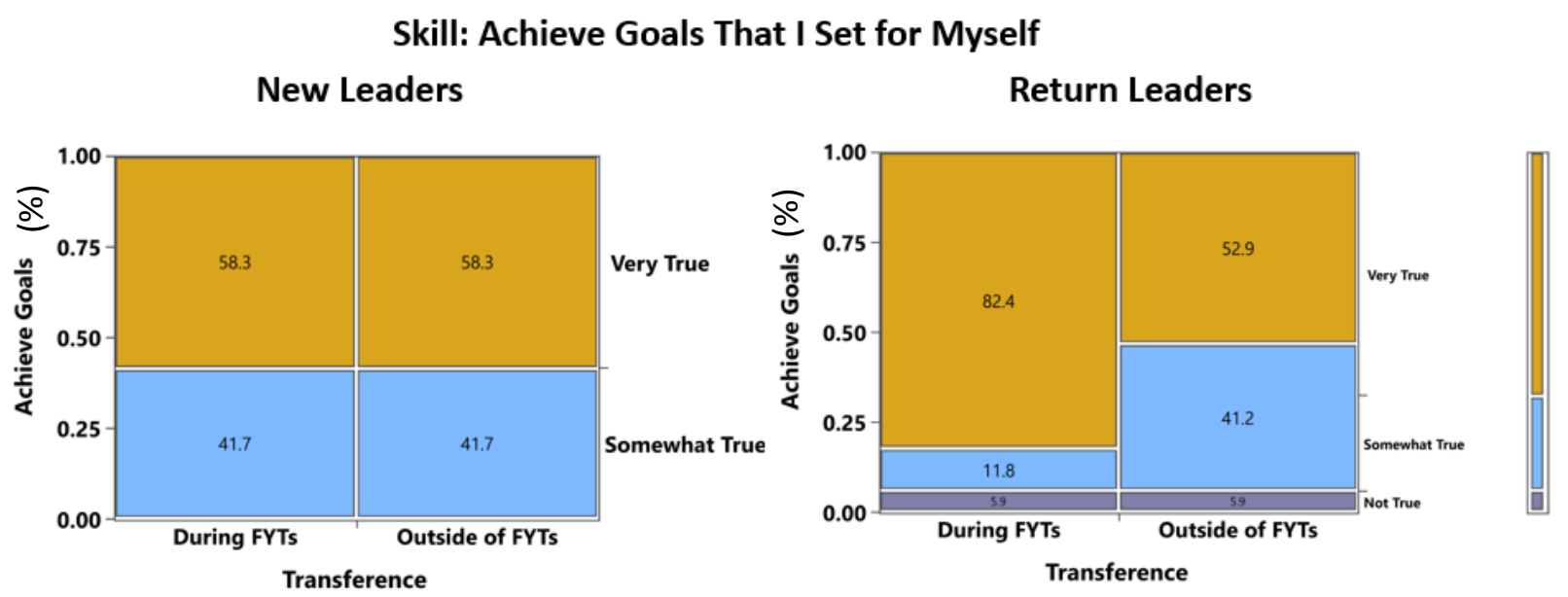

Next, examining leader ability to transfer skills related to self-efficacy, return leaders reported a higher confidence in the ability to achieve goals that they set for themselves $(82.4 \%)$ compared to their less experienced peers (58.3\%). When comparing the same groups outside of leading FYTs, new leaders reported the same level of confidence (58.3\%), while return leaders reported being less confident in their abilities to achieve their goals (52.9\%). Although not statistically significant, this suggests a possible pattern that more experienced leaders may have high confidence in using this skills during FYTs, but not all are able to transfer the skill to other areas of life. 
Figure 12. New vs Return Leader Confidence in Ability to Set Long Term Goals and Review Their Progress Regularly
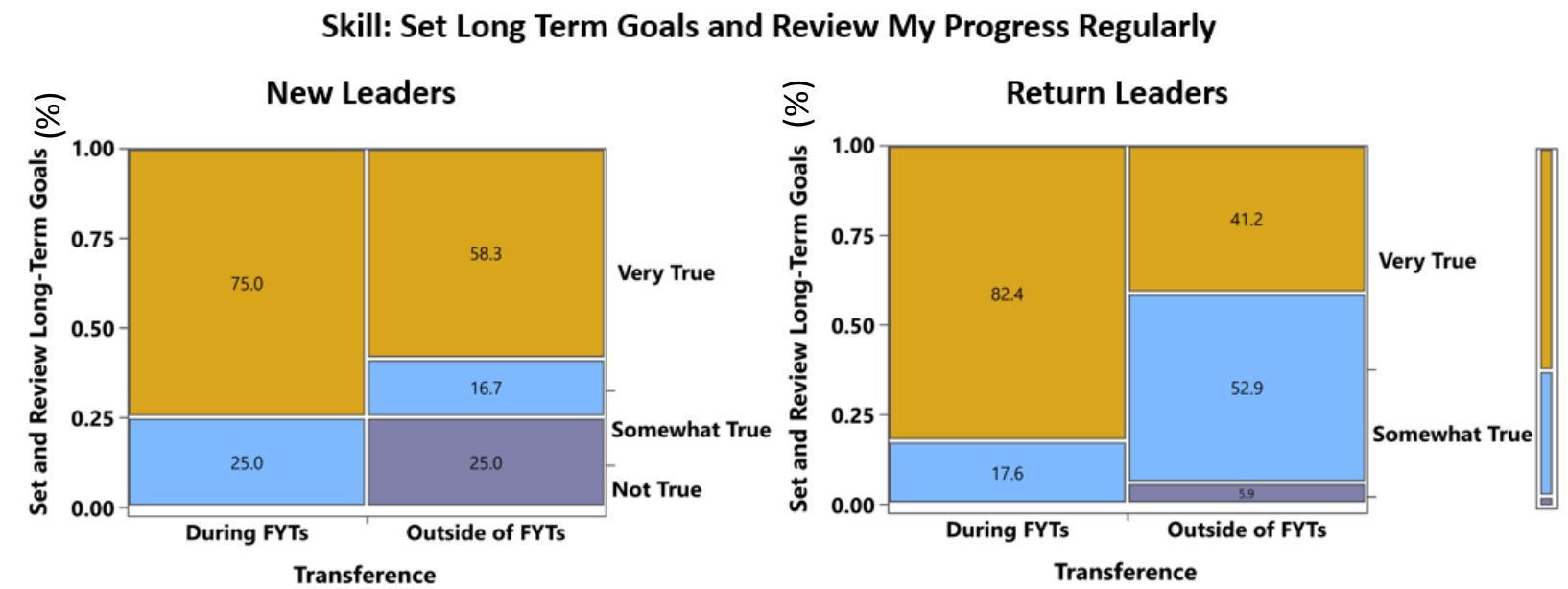

A similar pattern occurred for the skill of setting long term goals and reviewing progress regularly. Return leaders reported higher confidence $(82.4 \%)$ in their ability to use the skill during trips than new leaders $(75.0 \%)$, but they were less confident $(41.2 \%)$ using the skill outside of leading FYTs than new leaders (58.3\%). It is important to note that although return leaders experienced a larger reduction in confidence, the same grouping overall had 5.9\% report no ability to use this skill versus new leaders $(25.0 \%)$.

\section{Research Question 3}

R3: Does the level of involvement across other Adventure West Virginia program areas impact leaders' ability to transfer leadership skills to life outside of AWV?

Null-Hypothesis 3: There is no significant difference between leaders of varying experience levels (experience with other AWV program areas) when measuring transference of emotional intelligence and self-efficacy. 
A different method to compare leadership transference across FYT student leaders is the level of involvement across the AWV program. In order to compare these experience levels, researchers used question D7 to create two subgroups of the sample population: 1) Just FYT Leader (L) and 2) FYT Leader and More (L+). This separation assumes that leaders that work for other areas of the AWV program have more training and more opportunities to implement that training in the workplace; therefore, the FYT Leader and More groups has more experience. The same tests that were done for $\mathrm{H} 2$ were replicated for $\mathrm{H} 3$ replacing the grouping variable of New versus Return with Just Leader (L) versus Leader and More (L+). The questions with results that were analyzed include L3, L4, L6, and L7.

\section{L3 Analysis: FYT leadership skills compared to other WVU students}

Fisher's Exact test of independence was performed on the above variables as contingency tables in JMP due to the small sample size. The results of this analysis when controlling for Just Leaders (L) versus Leaders and More (L+) are shown in Table 15. When only examining responses across experience levels, there was no statistical significance difference between leaders across experience levels within AWV; leading researchers to fail to reject the null hypothesis of equal proportions at the $\alpha=0.05$ level.

Table 15. Group Difference of Leadership Ability Compared to Other WVU Students

Just leaders (L) or Leaders and More (L+)

Fisher's Exact Test

\begin{tabular}{cccc}
\hline$\underline{N}$ & $\underline{D F}$ & $\underline{R \text { Square }(U)}$ & $p$-value \\
\hline 29 & 3 & 0.0361 & 0.7646
\end{tabular}




\section{L4 Analysis: Expansion of leader abilities from FYTs outside of an AWV setting}

Fisher's Exact test of independence was performed on the above variables as contingency tables in JMP due to a small sample size of $N=29$. The results of these analyses on the independent variable of Just Leader (L) versus Leader and More (L+) are shown in Table 16. When only examining responses across experience levels, there was no statistical significance difference between leaders across experience levels within AWV; leading researchers to fail to reject the null hypothesis of equal proportions at the $\alpha=0.05$ level.

Table 16. Group Difference of the Expansion of Skills Outside of a Trip Leading Context

\begin{tabular}{|c|c|c|c|c|}
\hline \multicolumn{3}{|l|}{ Just Leaders or Leaders and More $(N=29)$} & \multicolumn{2}{|c|}{ Fisher's Exact Test } \\
\hline$\underline{\text { Skill }}$ & $\underline{\text { Skill Area }}$ & $\underline{D F}$ & $\underline{R}$ Square $(U)$ & p-value \\
\hline Situational Leadership & Emotional Intelligence & 2 & .0677 & .3771 \\
\hline Judgement and Decision Making & Self-Efficacy & 1 & .0097 & .7107 \\
\hline Giving and Receiving Feedback & Emotional Intelligence & 2 & .1048 & .2705 \\
\hline Risk Management & Self-Efficacy & 1 & .0021 & 1.000 \\
\hline Bystander Intervention & Emotional Intelligence & 3 & .0025 & 1.000 \\
\hline Wellness and Self-Care & Self-Efficacy & 3 & .0995 & .1016 \\
\hline Relationship and Community Building & Emotional Intelligence & 2 & .0148 & .8441 \\
\hline Managing Conflict & Emotional Intelligence & 2 & .0133 & .7079 \\
\hline
\end{tabular}




\section{L6 Analysis: Usefulness of leadership skills in settings outside of AWV}

Fisher's Exact test of independence was performed on the above variables as contingency tables in JMP due to a small sample size of $N=29$. The results of this analysis when controlling for New Leaders versus Return Leaders are shown in Table 17. When only examining responses across experience levels, there was no statistical significance difference between leaders across experience levels within AWV; leading researchers to fail to reject the null hypothesis of equal proportions at the $\alpha=0.05$ level.

Table 17. Group Differences of Usefulness of AWV Taught Leadership Skills to Other Settings

\begin{tabular}{lccc}
\hline \hline Just Leaders or Leaders and More $(N=29)$ & $\underline{-}$ & \multicolumn{2}{c}{ Fisher's Exact Test } \\
Social Environment & 3 & .0293 & .9299 \\
\hline On the WVU Campus & 3 & .0890 & .3992 \\
In the Community Outside of WVU & 3 & .0230 & .781 \\
Within Student Groups & 4 & .0908 & .2434 \\
With Friends/Roommates & 4 & .0383 & .7152 \\
With Family Members & 4 & .0592 & .7460 \\
In the Workplace & 4 & & \\
\hline
\end{tabular}

\section{L7 Analysis: Transference of emotional intelligence and self-efficacy from FYTs to other areas of life}

In order to compare this transference across varying experience levels, the CochranMantel-Haenszel Test (CMH) was used to control for Just Leader (JL) or Leader and More (L+). The comparison between L7\#1 scores and L7\#2 scores created a single $p$-value (row mean score difference). $\mathrm{CMH}$ tests yielded two statistically significant $p$-values: Manage my emotions effectively $(p=.0016)$ and Set long-term goals and review my progress regularly $(p=.0053)$. For those two skills alone, researchers rejected the null hypothesis of equal proportions at the $\alpha=$ 
0.05 level. For all other skills, researchers failed to reject the null hypothesis of equal proportions at the $\alpha=0.05$ level. Full results are shown below in Tale 18 .

Table 18. Group Difference of Transference of EI and SE Skills to Other Areas of Life

\begin{tabular}{|c|c|c|c|c|}
\hline \multicolumn{2}{|c|}{ Just leaders or Leaders and More $(N=29)$} & \multicolumn{3}{|c|}{ Cochran-Mantel-Haenszel Test } \\
\hline$\underline{\text { Skill Area }}$ & $\underline{\text { Skill }}$ & $\frac{\text { CMH Chi- }}{\underline{\text { Square }}}$ & $\underline{D F}$ & $\begin{array}{l}\frac{p \text {-value }}{(\text { row score by }} \\
\text { col. probability) }\end{array}$ \\
\hline \multirow[t]{4}{*}{ Emotional Intelligence } & Understand my emotions & 0.0633 & 1 & 0.8013 \\
\hline & Read people and their emotions & 3.3502 & 1 & 0.0672 \\
\hline & Manage my emotions effectively & 9.9377 & 1 & $0.0016 *$ \\
\hline & $\begin{array}{l}\text { Manage other's emotions } \\
\text { effectively }\end{array}$ & 2.9559 & 1 & 0.0856 \\
\hline \multirow[t]{2}{*}{ Self-Efficacy } & Achieve goals that I set for myself & 1.4119 & 1 & 0.2347 \\
\hline & $\begin{array}{l}\text { Set long-term goals and review my } \\
\text { progress regularly }\end{array}$ & 7.7855 & 1 & $0.0053 *$ \\
\hline
\end{tabular}

*Significant when adjusted for family wise error with Benjamini-Hochberg Procedure at .3 false discovery rate

Utilizing the Kappa Agreement Test, overall transference of skills was analyzed on groups divided by experience level (just leaders or leaders and more). Four skills were found to have high levels of agreement between during FYT and outside of FYT settings: understand my emotions $(p=.0106)$, read people and their emotions effectively $(p=.0047)$, and manage my own emotions effectively ( $p=.0276)$, manage others' emotions $(p=.0259)$. The group that experienced this significant skill transfer agreement was leaders that held additional positions within the AWV program. Leaders that only held the FYT leader position experienced no significant skill transfer agreement. Three of these skills are related more closely with emotional intelligence and are the same skills that had high agreement for return leaders in research 
question 2. The additional skill, Set long term goals and review my progress regularly, is more related to self-efficacy. Results are shown in Table 19.

Table 19. Transference of Emotional Intelligence and Self-Efficacy Skills to Other Areas of Life Measured by Agreement Test (Kappa) and Bowker's Test of Symmetry of Disagreement

\begin{tabular}{|c|c|c|c|c|c|}
\hline \multicolumn{2}{|c|}{ Transference (During FYTs vs. Outside FYTs) } & \multicolumn{2}{|c|}{$\begin{array}{l}\text { Test of Agreement } \\
\text { (Kappa) }\end{array}$} & \multicolumn{2}{|c|}{$\begin{array}{l}\text { Bowker's Test of } \\
\text { Symmetry of Disagreement }\end{array}$} \\
\hline $\begin{array}{l}\text { Leadership } \\
\underline{\text { Experience }}\end{array}$ & $\underline{\text { Skill }}$ & $\underline{\text { Kappa }}$ & $\underline{\text { Prob }>z}$ & Chi-Square & $\underline{\text { Prob }>C h i S q}$ \\
\hline \multirow[t]{6}{*}{ Just Leaders } & Understand my emotions & .2558 & .1144 & 2.8 & .4235 \\
\hline & Read people and their emotions & .2 & .1648 & 3.5714 & .0588 \\
\hline & Manage my emotions effectively & .1351 & .2237 & 4.5714 & .206 \\
\hline & $\begin{array}{l}\text { Manage other's emotions } \\
\text { effectively }\end{array}$ & .1273 & .1954 & 6 & .1116 \\
\hline & $\begin{array}{l}\text { Achieve goals that I set for } \\
\text { myself }\end{array}$ & .0959 & .3039 & 2 & .5724 \\
\hline & $\begin{array}{l}\text { Set long-term goals and review } \\
\text { my progress regularly }\end{array}$ & -.1 & .2525 & 5.285 & .152 \\
\hline \multirow{6}{*}{$\begin{array}{l}\text { Leaders and } \\
\text { More }\end{array}$} & Understand my emotions & .6389 & $.0106 *$ & 0 & 1 \\
\hline & Read people and their emotions & .6829 & $.0047 *$ & 2 & .1573 \\
\hline & Manage my emotions effectively & N/A & N/A & N/A & N/A \\
\hline & $\begin{array}{l}\text { Manage other's emotions } \\
\text { effectively }\end{array}$ & -.4348 & .0276 & 4 & .2615 \\
\hline & $\begin{array}{l}\text { Achieve goals that I set for } \\
\text { myself }\end{array}$ & .4179 & .0623 & .333 & .5637 \\
\hline & $\begin{array}{l}\text { Set long-term goals and review } \\
\text { my progress regularly }\end{array}$ & .4507 & $.0259 *$ & 3 & .0833 \\
\hline
\end{tabular}

*Denotes significant agreement between During and Outside FYTs for Kappa test, and asymmetry of the specific skill scores During and Outside FYTs at the $\alpha=0.05$ level 
In order to gain insight into how leaders of different experience levels transfer each skill, mosaic plots were used for comparison. These plots allow researchers to compare each group's transference in order to see if one group showed patterns of higher transference. The patterns shown in these plots are supported by significant agreement values found by the Kappa test of agreement in Table 14. This section is broken into two sub-sections: emotional intelligence skills and self-efficacy skills.

\section{Emotional Intelligence}

Figure 13. JL and L+ Confidence in Ability to Understand Their Emotions
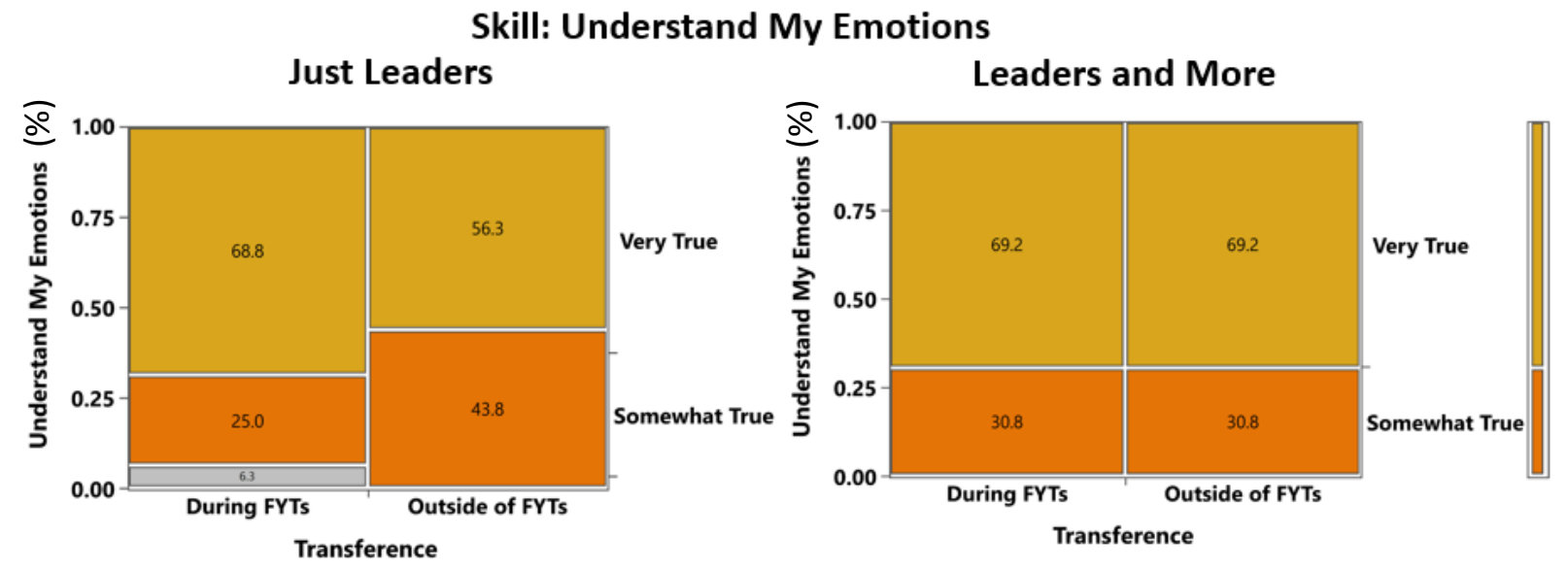

Beginning with skills related to emotional intelligence, leaders were asked to report their confidence in their ability to read their own emotions. Respondents that were just FYT leaders reported a reduced confidence when transferring the skill outside of FYTs from $68.8 \%$ to $56.3 \%$ while leaders that held other positions within AWV reported no difference in confidence during and outside of trips (69.2\%). Although not statistically significant, this suggests that leaders that hold more positions within AWV are better able to transfer this skill. 
Figure 14. JL and L+ Confidence in Ability to Read People and Their Emotions

Skill: Read People and Their Emotions
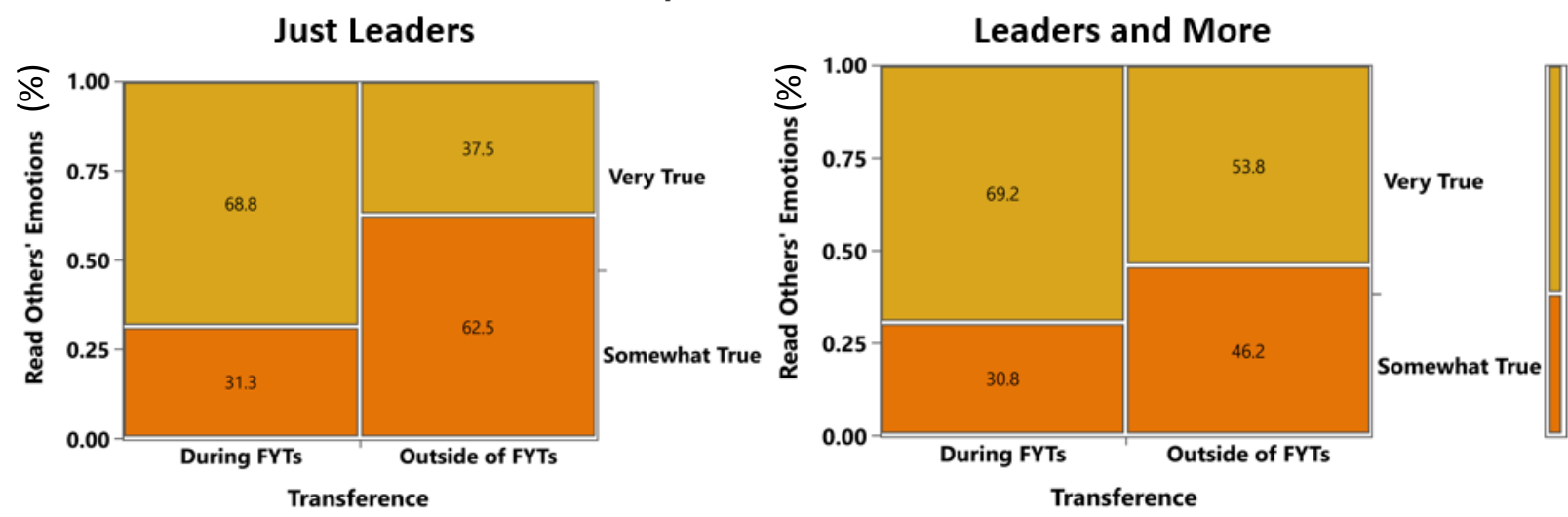

When asked to report their confidence of their ability to read people and their emotions, respondents that were only FYT leaders reported a confidence level of $68.8 \%$ while leading FYTs that reduced to $37.5 \%$ when in settings outside of FYTs. That reduction was larger than that reported by leaders with additional positions $(69.2 \%, 37.5 \%)$. Although not statistically significant, this suggests that more experienced leaders are better able to transfer this skill than less experienced leaders.

Figure 15. JL and L+ Confidence in Ability to Manage Their Own Emotions Skill: Manage My Own Emotions
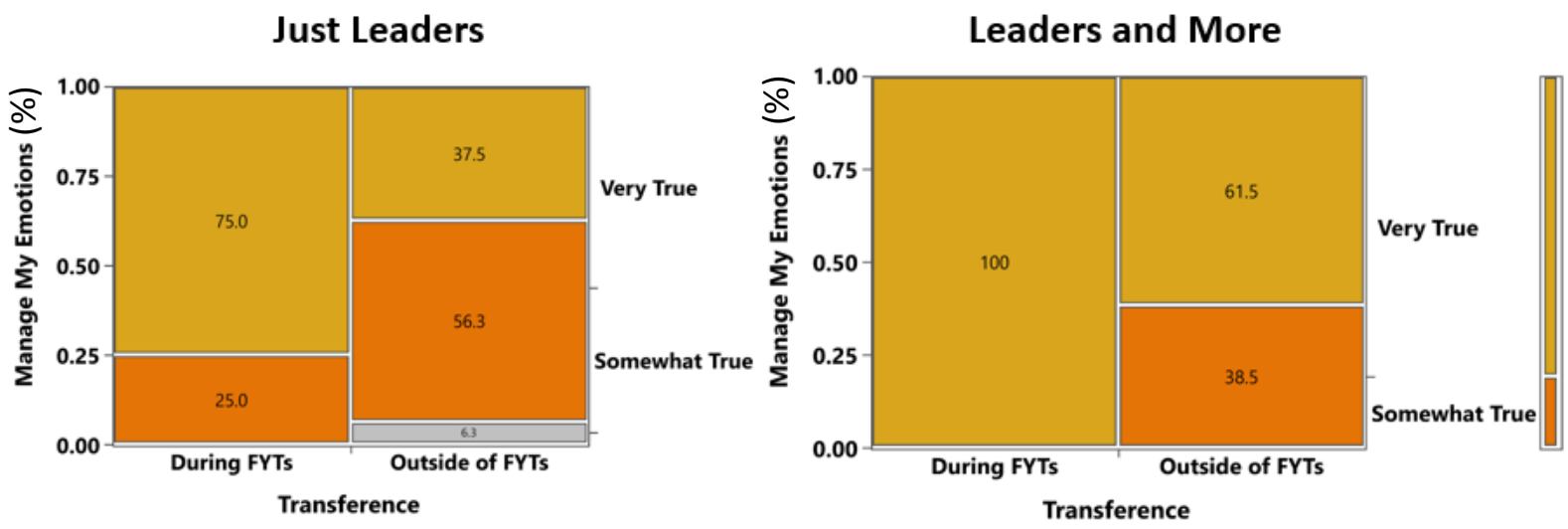
A similar trend was reported regarding student leader confidence in ability to manage their emotions. Respondents that were only leaders went from $75.0 \%$ confidence in this skill during trips to $37.5 \%$ confidence outside of trips. Meanwhile respondents that were leaders and held an additional position within AWV reported a confidence level of $100 \%$ during FYTs to $61.5 \%$ outside of FYTs. This suggests that more experienced leaders (L+) are better able to transfer this skill than less experienced leaders (JL). Statistical results are shown in Table 15.

Figure 16. JL and L+Confidence in Ability to Manage Others' Emotions Effectively

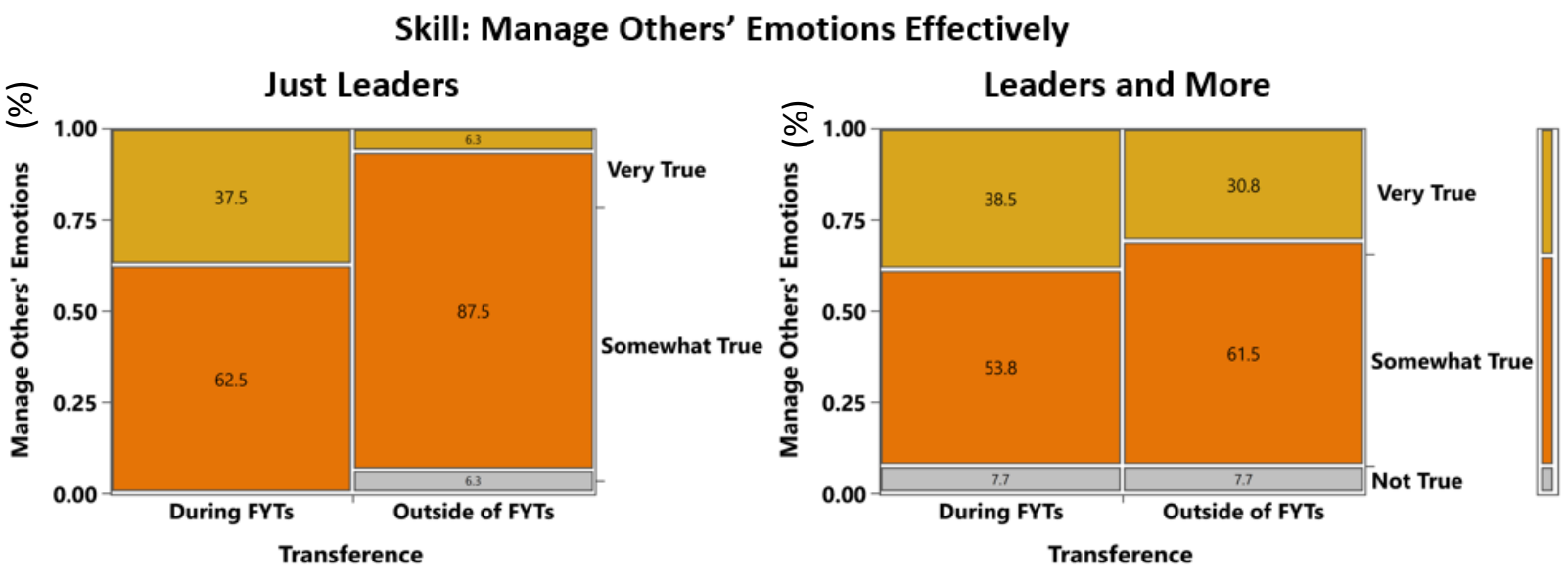

Both groups reported a lack of confidence in their ability to manage others' emotions both during and outside of trips. Less experienced leaders went from $37.5 \%$ confidence during trips to just $6.3 \%$ outside of trips, while more experienced leaders went from $38.5 \%$ during trips to $30.8 \%$ outside of trips. Although not statistically significant, this suggests that more experienced leaders are better able to transfer this skill than less experienced leaders. Overall, this skill remains the skill that leaders are least confident in in either setting. 


\section{$\underline{\text { Self-Efficacy }}$}

Figure 18. JL and L+Confidence in Ability to Achieve Goals They Set for Themselves

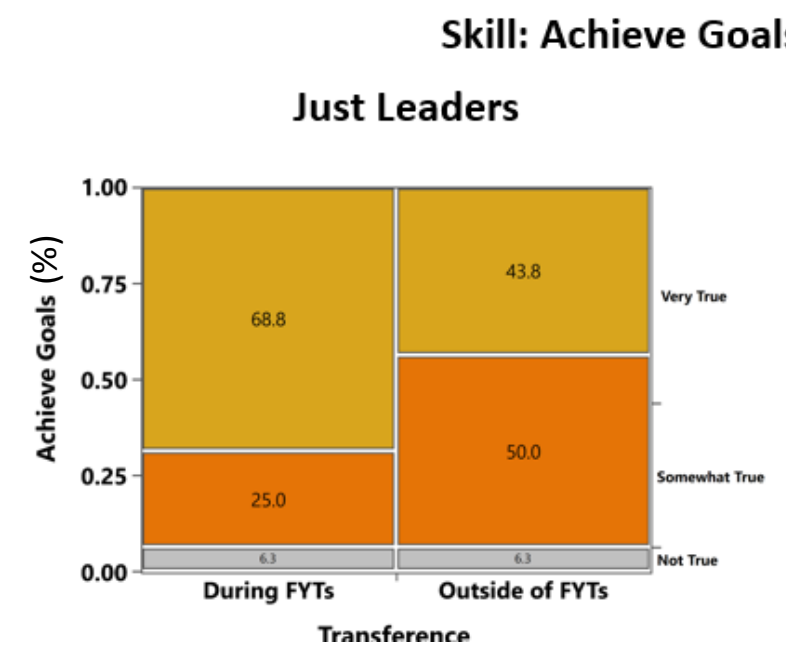

Skill: Achieve Goals That I Set for Myself

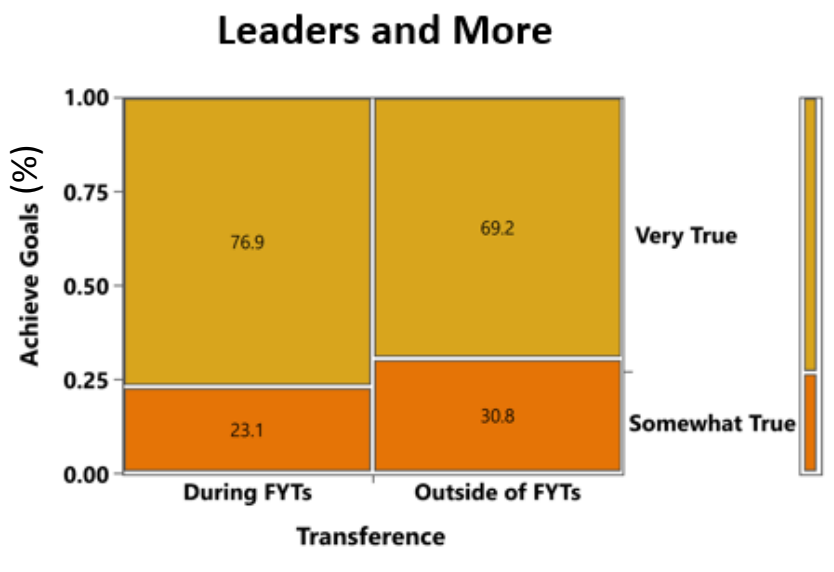

Next, examining difference of ability to use self-efficacy skills, leaders that held

additional positions within AWV reported being more confident in their ability to achieve goals they set for themselves during (76.9\%) and outside of trips (69.2\%). Respondents that were only FYT leaders reported a confidence level of $68.8 \%$ during and $43.8 \%$ outside of leading FYTs. Although not statistically significant, this suggests that more experienced leaders are better able to transfer this skill than less experienced leaders.

Figure 19. JL and L+ Confidence in Ability to Set Long Term Goals and Review Their

\section{Progress Regularly}
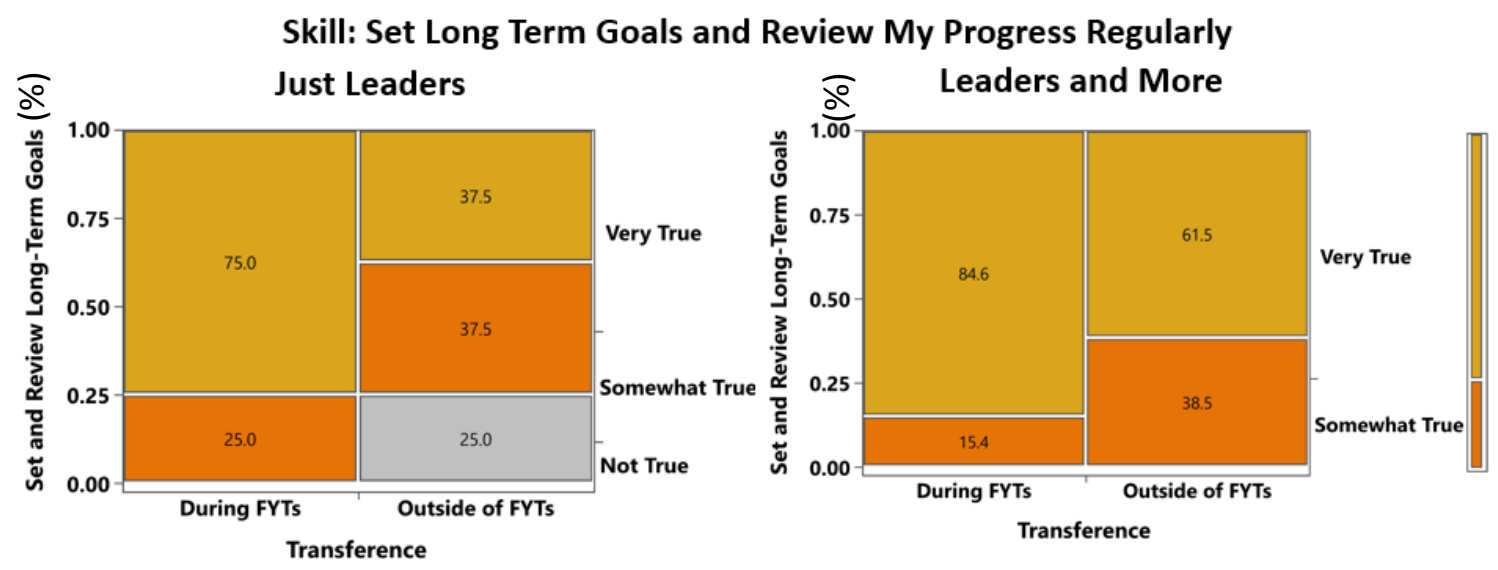
Finally, respondents that were only FYT leaders were significantly less confident transferring their ability to set long term goals and review their progress regularly $(75.0 \%$, $37.5 \%)$ than respondents that were FYT leaders with additional positions within AWV (84.6\%, $61.5 \%)$. This suggests that more experienced leaders $(\mathrm{J}+)$ are better able to transfer this skill than less experienced leaders (J). Statistical results are shown in Table 15.

\section{Summary}

The results presented in this chapter provide key insight to how student leaders within Adventure West Virginia are learning and utilizing their leadership skills in areas of life outside of the FYT program. These results lead to a variety of conclusions and implications for researchers which will be discussed in the following chapter. To summarize the results shown above, we must examine all three research questions separately. Research Question 1 examined the differences between various experience levels of FYT student leaders including New versus Return Leaders and Number of Trips Led. From these results, researchers were able to decide to continue researching further questions using only the independent variable New versus Return Leader due to a smaller number of groups. Leaders with more experience rated themselves as higher than their WVU peers when considering their leadership skills (Table 6). Other than survey question L3, there were no significant differences among leaders of varying experience. Research Question 2 examined leadership skill transference from within FYTs to other areas of life. Researchers tested to see if there was skill transference among the entire FYT student leader population and found that leaders were not reporting significant transference of skills. When grouping based for leader experience levels (New versus Return Leader), two skills showed a significant correlation between leader experience and skills transference: managing their own emotions effectively (better transferred by return leaders) and setting long-term goals 
and review their progress regularly (better transferred by new leaders) (Table 12). Other skill analyses show differences among groups regarding skill transfer but were not statistically significant.

Research Question 3 attempted to examine the same skill transference across a different kind of experience level: student leaders who are only FYT leaders and student leaders that hold additional positions for other program areas of AWV. Researchers found that leaders that were more experienced, in this case the ones that held more than one position within the AWV program, reported being able to better transfer certain leadership skills than their less experienced peers (Table 15). Again, the two skills that were statistically significant when testing for their transference were Manage my own emotions and Set long-term goals and review their progress regularly. The following chapter will discuss these results and their implications for the AWV and future research. Other skill analyses show differences among groups regarding skill transfer but were not statistically significant. 


\section{Chapter 5 \\ Discussion}

This final chapter attempts to bring meaning to the results of the data collected during this research project. Additionally, the goal of this section is to link the results of this research to the current field of study regarding the transference of leadership skills among trip leaders in outdoor orientation programs. To understand the results of this research and it's connection to previous studies, this section focuses on addressing the study's research questions and correlating results. Limitations of the study as well as implications for future research and practice are also covered.

The purpose of this study included three broad areas. First, analyses were conducted to examine self-perceived leadership skills varied depending on the experience level of those leaders. Second, the study compared two groups of leaders with varying experience levels (New versus Return Leader) to examine if there was significant difference in the transference level of those skills into other areas of life. Finally, as a different way to categorize leaders, researchers compared leaders that only led FYT trips for AWV and those that led FYTs and had held other positions for AWV. This chapter is organized using the research questions as a framework.

Previous studies have found that outdoor education programs, specifically outdoor orientation programs have the ability to increase student success and retention (Ewert \& McAvoy, 2000; Hattie et al., 1997; Fielding \& Hogg, 1997; Bandura, 1969; and Bell \& Starbuck, 2017). While there is significant background research of the benefits of these programs on participants, there is a lack of understanding about how leading these programs affect trip leaders, specifically peer student trip leaders. Two increasingly researched constructs for identifying effective leaders are emotional intelligence and self-efficacy (Palmer, Walls, 
Burgess, \& Stough, 2001; Propst \& Koessler, 1998). Initial research by Hattie er al. (1997) found that adventure programs were found to have a positive impact on leaders' social competencies including aspects directly related to emotional intelligence and self-efficacy. Other studies have found correlations between emotional intelligence and self-efficacy and training which supports the idea that these may be traits that can be learned and built upon (King, 1999; Purkable, 2003). Where the research gap remains, is how well student leaders transfer these skills to life outside of their leadership role. The research questions listed below attempt to fill this gap by examining Adventure WV student leaders' abilities to use skills related to emotional intelligence and selfefficacy while leading First Year Trips (FYTs) and in settings outside of leading FYTs.

\section{Research Question 1}

Through research proposed prior to data collection, one of the main intentions of this project was to determine if there was a difference in self-perceived leadership skills among FYT leaders depending on experience level. Although previous studies have shown there to be a positive correlation between emotional intelligence and self-efficacy skills and leadership experience (Aguir,1986; Hayashi \& Ewert, 2006; and Jacobs, 2004), the Adventure West Virginia program wanted to examine the effectiveness of their FYT training curriculum designed specifically to strengthen these skills within their leaders.

In order to analyze correlational data, two types of ratio data were tested to separate FYT leaders with varying degrees of experience related to time: New versus Return Leaders (Two groupings) and Number of Trips Led (5 groups). The grouping variable of New versus Return Leaders provided better results, statistically as the small sample was split across two groups instead of five. This study found that FYT $(\mathrm{N}=29)$ had positive reviews and feelings regarding their experience working for Adventure WV. Almost all leaders said that they would not only 
recommend participating in an FYT trip, but they would recommend applying to become an FYT leader. Similarly, all but one leader reported that leading FYTs had a positive impact on their leadership ability. While these results are important for AWV's overall view of how their leaders feel about the program, we wanted to see if leader responses varied relative to their experience level.

The results suggest a trend that more experienced leaders believed that their leadership skills were above average compared to other students at WVU. This supports previous research such as Bell and Starbuck's (2017) finding that as leaders gained more experience, they became more confident in their perceptions of their overall leadership ability. However, when examining specific skills related to emotional intelligence and self-efficacy, researchers found no statistically significant differences between new or return leaders' abilities. Similar results were found for differences between groups based on the actual number of trips led. While there were no differences between leader experience levels, there was a trend that student leaders thought that leading FYTs for AWV had improved their leadership ability, which is still considered a success for AWV and their training methods and also supported by Bell and Starbuck's 2017 research study.

\section{Research Question 2}

The concept of transference is at the heart of the debate concerning the effectiveness of adventure education programs as a viable and reliable form of education, (Cummings, 2009). Previous researchers have argued that the true value or effectiveness of a program lies in how the skills attained during an adventure activity will serve the learner in the future (Gass, 1999; Neill, 2007; Cummings, 2009). In the context of higher education, students participating in outdoor education activities could greatly benefit from the transference of certain skills from the outdoors 
to the high stress environment of college. This study attempted to examine this transference among AWV student trip leaders. Overall, leaders reported that they were able to transfer skills taught in AWV trainings and reinforced through trip leading to areas outside of a trip leading context. The skills that leaders said were the most expanded include giving and receiving feedback (emotional intelligence), relationship and community building (emotional intelligence), and judgement and decision making (self-efficacy). One specific skill, Wellness and Self-Care, was found to be potentially transferred more often by more experienced leaders. This is an interesting finding as wellness and self-care is the most fundamentally individual skill studied within emotional intelligence and may perhaps be the most transferable due to it only involving the individual using it.

When examining the level of transference of emotional intelligence and self-efficacy skills, results indicate that leaders were generally less confident in their ability to use leadership skills outside of a trip leading context. This supports previous research that it is more difficult to use leadership skills outside of a leadership role than during, and that transference of these skills increases with more experience (Cummings, 1999; Bacon, 1990). Three specific skills were found to be significantly lower when leaders reported their confidence in ability to use them outside of FYTs: Reading people and their emotions, Managing one's own and other's emotions effectively, and Setting long-term goals and reviewing progress regularly. The results supported by two independent analyses (CMH and Bowker's Test of Symmetry) demonstrated that leaders thought these four skills were the most difficult to transfer to settings outside of leading trips. Although leader confidence in ability to use skills during trips was higher than that in other settings, several skills were still found to be transferred to some degree depending on leader experience. 
Researchers found that overall, leaders reported they were successfully transferring the ability to understand their emotions during and outside of a trip leading setting. This finding supports previous research by Hayashi and Ewert (2006) and Jacobs (2004) where not only did leaders with more experience report higher levels of emotional intelligence, but emotional intelligence skills were more likely to be transferred if they involved intrapersonal components. While arguably the easiest skill to transfer due to it being an intrapersonal skills (Propst Koessler, 1998), this finding is still successful and can be used as a baseline for future skill transference. When a Kappa analysis was done for each leadership experience group separately, the return leaders had significant moderate agreement in three emotional intelligence skills while new leaders had none. Specifically, return leaders were better able to transfer their ability to understand their own emotions, read people and their emotions, and manage other's emotions effectively in a setting outside of FYTs than their newer colleagues.

This was the similar for the skill of achieving goals that one sets for oneself. While leading FYTs, more experienced leaders consistently reported having higher confidence in skills compared to their less experienced peers. That confidence, however, dropped almost $30 \%$ when transferring those same skills to settings outside of FYTs. This was also supported by the lack of agreement by the Kappa coefficient. For most skills, more experienced leaders that initially reported high confidence in skills while leading FYTs, reported being less confident in using those skills in other areas of life. Less experienced leaders appeared to transfer their confidence well; however, the proportion of them having high confidence in both settings was low. No previous research studies have found or explored this trend, and further research is recommended to find a cause. Many programs advocate for their leaders to be humble and preach that an overly confident leader could pose significant risks when making decisions for a group (Miner, 1999). 
Another thought is that perhaps as leaders gain more experience applying the lessons they are taught to the field, they are better able see where they actually fall on the spectrum of leadership.

A potential explanation for above finding is the Dunning-Kruger Effect which attempts to explain the phenomenon where less experienced people tend to think that they are better at certain skills than they actually are (Dunning, 2011). It may be possible that leaders that had only recently experienced leader training and the experiences that come with leading their first summer of FYTs are more confident in their ability to use those skills in other areas of life. On the other end, more experienced leaders may have a better understanding of those skills while leading trips but are able to recognize where they fall short in transferring them. Further research is recommended to attempt to explain this observation.

\section{Research Question 3}

Propst and Koessler found that the higher one's self-efficacy, the more likely they are to pursue leadership opportunities (1998). While physical time in the field or seasons under one's belt can be used as a predictor of experience level, the amount of involvement across the AWV program may also give us insight to how well leaders are transferring their skills. Previous research has found that transference occurs more when an individual has more, novel opportunities to implement a new skill (Marsh et al., 1986; Propst \& Koessler, 1998; Paxton \& McAvoy, 200; Kellert, 1999; Sibthorp et al., 2008; Benson, 2018). In the context of this study, student leaders that work in other program areas within AWV may have more, novel opportunities to transfer their leadership skills to. In order to see if this additional experience had an impact on leader skill transference, researchers compared the two groups.

When testing for transference of skills among leaders of different experience levels, specifically students who are just leaders compared to those that hold additional positions within 
Adventure WV, researchers found results that support those of Marsh et al., 1986; Propst \& Koessler, 1998; Paxton \& McAvoy, 200; Kellert, 1999; Sibthorp et al., 2008; Benson, 2018. For every skill tested, leaders that held additional positions within AWV reported better transference than their peers that only lead FYTs. While this was not an original goal of the study, it is certainly the most interesting and potentially influential finding for future research. This was supported by the Kappa agreement analysis for each skill separately, where the leaders holding additional positions had significantly moderate agreement in three emotional skills while those only leading FYTs had none. Specifically, the agreement between during and outside settings for return leaders to understand their own emotions, read people and their emotions, and manage other's emotions effectively was higher than that of leaders that only led FYTs.

While there have been previous studies on the transference of leadership skills across varying levels of experience, no previous research was found to specifically look at transference across leaders with varying levels of involvement within their program. Future research is recommended to build upon Propst and Koessler's work of comparing different forms and frequencies of feedback to include the grouping variable of different areas of implementation of leadership skills.

\section{Limitations}

The most fundamental limitation to the research conducted in this study was the small sample size $(\mathrm{N}=29)$ and its effect on analyses and significant results. Due to errors made during the creation and administration of the survey, five answer sets were found to be incomplete and were removed from the total sample. This required the use of non-parametric analyses, which even though were carried out accordingly, were still limited in results from the small sample. Suggestions for future research with this population include broadening the range of years to 
include trip seasons before 2017 and providing additional meaning and context for the value of the study in the survey email.

Because the sample population included leaders that were active over the period of three years, there was high variability in age and external experience levels of respondents. For example, two respondents reported that their first season leading FYTs was in 2014 which means they are likely several years older than any leader that reported their first year to be 2019 . The skills studied in this research could be learned and built upon in areas of life other than the AWV program, and therefore, older respondents may inherently have higher levels of those skills which is not calculated for in this study. Future research should consider ways to identify and adjust for this variance as well as the difference in leader trainings year-to-year.

Another limitation that must be considered is the variance that exists within each grouping variable. New and Return Leader groups were created based on respondents reporting of the year of their first trip (2014-2019). Even though this accounts for one season or more, each leader could lead 1-4 trips per season which is why researchers also tried to use the grouping variable of number of trips led. Future research should consider having respondents quantify exactly how much experience they have leading FYTs for AWV such as exactly how many trips they have led. Another consideration would be to compare skills and transference based on type of trip as the nature of FYT trip models involve different activities and difficulties.

Finally, due to the timing of the study, researchers were limited to measuring selfperceived skill transference. While this is a valid method to measuring these skills, the incorporation of a true control group of WVU students that do not work for AWV would allow for more direct comparison between leader and non-leader abilities. Likewise, this would increase the sample size, allowing for other statistical analyses to be utilized similar to previous 
research. Future research should consider using a similar survey in a pre-post survey design method that is given before leader training, after leader training but before the summer season of FYTs, and finally at the end of the summer FYT season.

\section{Implications for Research and Practice}

The research in this thesis is relevant and has implications for current research involving leadership growth and outdoor orientation programs. This research is important because by creating learning and work environments for our leaders that fosters this transference, we will be better preparing our student leaders and participants for life during and after college. By understanding which groups of leaders transfer these skills best, we can adapt our training curriculum to strengthen the skills that are more difficult to transfer such as managing others' emotions and setting and reviewing long term goals. While it is not surprising that more experienced leaders usually saw better transference of skills, it would be interesting to compare that level of transference across each program area of AWV as each has its own mission, goals, and staff training. Likewise, it would be interesting to attempt to study the reasoning behind why leaders that had worked more seasons felt like they were less able to transfer certain skills through the use of a qualitative study. In any case, future research should focus on the utilization of a true control group, comparing student leader confidence levels to corresponding traditional undergraduate students.

In terms of professional practice, this study's results imply that in order to encourage leadership growth within our adventure leaders, participants, and community, collegiate outdoor adventure programs should develop and adjust trainings specific to the needs of their leaders. Introducing leaders to more novel situations during staff trainings will allow them to incorporate what they are learning to better solidify and transfer it to other areas of life later on. Similarly, 
designing specific curriculum for leader trainings that teach the foundations of emotional intelligence and self-efficacy would potentially allow leaders to have something to build upon with their experiences in the field with groups. Also, supporting Stephen Bacon's research, more emphasis on group processing in the form of daily coleader debriefs and intentional end-of-trip debriefs with managers is recommended to foster an increased transference.

This study brings insight into the Adventure WV student leader population and their strengths and weaknesses in transferring leadership skills. Results of the data set and analysis of this thesis suggest that although student leaders believe leading FYTs has had a positive impact on their leadership ability, more leadership experience does not always directly correlate to higher leader confidence and preparedness. The Adventure WV program, with this insight, should consider encouraging more overlap of student employees across its various programs as each adds to the base of skills taught during FYT training.

\section{Conclusion}

For the field of outdoor adventure education, this study holds interesting findings that could lead to a broader understanding of how program leaders are developing. While every outdoor program varies in how it trains its leaders, research that attempts to understand exactly how leadership development works and ways that we as educators can better foster transference of necessary skills is relevant and applicable. Programs such as NOLS and Outward Bound that have various programmatic roles including trip leader, logistics, and management may benefit from adjusting their opportunities to include more crossover of responsibilities and training. Collegiate programs should look at how their trainings are preparing their student trip leaders not only for the outdoors, but for a part of life that is potentially much scarier: adulthood. While knowing how to make a good campfire is useful, being able to express compassion, empathy, 
and self-awareness is far more important in the world we live in today. As Kurt Hahn, founder of Outward Bound stated, "The foremost task of education is to insure the survival of these qualities: an enterprising curiosity, an undefeatable spirit, tenacity in pursuit, readiness for sensible self-denial, and above all, compassion." Fundamentally, our role as outdoor educators is to instill in others a knowledge and passion of the world around us. In doing so, may we not only guide the next generation towards a better future, but once again become students ourselves. 


\section{References}

Aguiar, J. D. (1986). Analysis of successful adventure leaders. Unpublished doctoral dissertation, Boston University, Boston.

Bacon, S. (1990). The evolution of the Outward Bound process. In A. Easley, J. Passineau, \& B. Driver (Eds.), The use of wilderness for personal growth, therapy, and education (pp. 38- 51). USDA Forest Service, General Technical Report RM-193.

Bandura, A. (1977). Self-efficacy: Toward a unifying theory of behavioral change. Psychological Review, 84, 191-215.

Bandura, A. (1986). Social foundations of thought and action: A social cognitive theory. Englewood Cliffs, NJ: Prentice Hall.

Bandura, A., \& Schunk, D. H. (1981). Cultivating competence, self-efficacy, and intrinsic interest through proximal self-motivation. Journal of personality and social psychology, 41(3), 586.

Barling, J., Slater, F., \& Kelloway, E. K. (2000). Transformational leadership and emotional intelligence: An exploratory study. Leadership \& Organization Development Journal.

Baumeister, R. F., \& Tice, D. M. (1990). Point-counterpoints: Anxiety and social exclusion. Journal of Social and Clinical Psychology, 9(2), 165.

Belknap, Coy James III, "The Impacts of an Outdoor Orientation Program on Participants' Self Evaluated Trait Emotional Intelligence" (2011). Graduate Theses, Dissertations, and Problem Reports. 4694.

Benjamini, Y., \& Hochberg, Y. (1995). Controlling the false discovery rate: a practical and powerful approach to multiple testing. Journal of the Royal statistical society: series B (Methodological), 57(1), 289-300.

Berger, J.B., \& Lyon, S.C. (2012). Past to Present A Historical Look at Retention. In A. Siedman (Ed.), (2005). College Student Retention: Formula for Student Success. Greenwood Publishing Group.

Buell, L. (1983). The 24-Hour Experience: An Outdoor Adventure Program. Greenfield, MA: Environmental Awareness Publications.

Benson, L. (2018) Permanency of Leader Self-Confidence Development: A Longitudinal Comparative Analysis. PEOPLE: International Journal of Social Sciences, 4(2), 906-931.

Bell, B., Holmes, M. R., \& Williams, B. G. (2010). A census of outdoor orientation programs at four-year colleges in the United States. Journal of Experiential Education, 33, 1-18.

https://doi.org/10.1177/105382591003300102

Bell, B., \& Starbuck, D. (2017). Outdoor Orientation Leaders: The Effects of Peer Leadership. The Journal of Outdoor Recreation, Education, and Leadership. 9(3), 280-297.

Ciarrochi, J. V., Chan, A. Y. C., Caputi, P. (2000). A critical evaluation of the emotional intelligence construct. Personality and Individual Differences, 28(3), 539-561. 
Caizzi, E., Parish, M., Mackley, S., Arun, N., West, D., \& Otunuga, O. (2018). Evidence Review: An evaluation of the impact of adventure learning and leadership programmes on young people's selfesteem, self-confidence and resilience.

Cohen, J. 1960. A coefficient of agreement for nominal data, Educational and Psychological Measurement, 20: $37-46$

Cooper, A. \& Petrides, K. V. (2010). A psychometric analysis of the Trait Emotional Intelligence Questionnaire-Short Form (TEIQue-SF) using Item Response Theory. Journal of Personality Assessment, 92, 449-457

Cummings, J. P. (2009). A longitudinal study of the outcomes from participation in wilderness adventure education programs.

Dack, Cory Maria. (2010) The Life Effectiveness of Wilderness Adventure Leaders. Thesis. Paper 280.

Dewey, J. (1938). Experience and Education. New York: Collier Books.

Dunning, D. (2011). The Dunning-Kruger effect: On being ignorant of one's own ignorance. In Advances in experimental social psychology (Vol. 44, pp. 247-296). Academic Press.

Ewert, A. (1983). Outdoor adventure and self-concept: A research analysis. Eugene, OR: Center of Leisure Studies, University of Oregon.

Ewert, A., \& McAvoy, L. (2000). The effects of wilderness settings on organized groups: A state-ofknowledge paper. USDA Forest Service Proceedings, 15(3), 13-26.

Fielding, K., \& Hogg, M. (1997). Social identity, self-categorization, and leadership: A field study of small interactive groups. Group-Dynamics, 1(1), 39-51.

Frauman, E., \& Waryold, D. (2009). Impact of a Wilderness Orientation Program on College Student's Life Effectiveness. Journal of Outdoor Recreation, Education, and Leadership. 1(2), 189-207.

Gager, Ron. (1977). Experiential education: Strengthening the learning process. Unpublished manuscript, Colorado Outward Bound School, Denver, Colorado.

Gass, M. (1999). Transfer of learning in adventure programming. In J.C. Miles \& S. Priest (Eds.), Adventure programming (pp. 227-233). State College, PA: Venture Publishing.

Gass, M. A., Gillis, H. L., \& Russell, K. C. (2012). Adventure therapy: Theory, practice, \& research.

George, J. M. (2000). Emotions and leadership: The role of emotional intelligence. Human relations, 53(8), 1027-1055.

Goldenberg, M., McAvoy, L., \& Klenosky, D. B. (2005). Outcomes from the components of an Outward Bound experience. Journal of Experiential Education, 28(2), 123-146.

Goleman, D. (2001). An EI-based theory of performance. The emotionally intelligent workplace: How to select for, measure, and improve emotional intelligence in individuals, groups, and organizations, 1, 27-44. 
Goleman, D. (2017). What Makes a Leader?(Harvard Business Review Classics). Harvard Business Press.

Graham, J. (1997). Outdoor leadership: Technique, common sense \& self-confidence. The Mountaineers Books.

Grandey, A. A. (2000). Emotional regulation in the workplace: A new way to conceptualize emotional labor. Journal of occupational health psychology, 5(1), 95.

Greene, J. (2017). Sense of Place and Belongingness in Outdoor Orientation Programming.

Hartsfield, M. K. (2003). The internal dynamics of transformational leadership: Effects of spirituality, emotional intelligence, and self-efficacy. Unpublished doctoral dissertation, Regent University, Virginia Beach.

Hattie, J., Marsh, H., Neill, J., \& Richards, G. (1997). Adventure education and Outward Bound: Out-of-class experiences that make a lasting difference. Review of Educational Research, 67(1), 43-87.

Hayashi, Ayako. (2006) Leadership development through an outdoor leadership program focusing on emotional intelligence. Thesis.

Hayashi, A., \& Ewert, A. (2006). Outdoor leaders' emotional intelligence and transformational leadership. Journal of Experiential Education, 28(3), 222-242.

Hunt, J. (1999). Philosophy of adventure education. In J.C. Miles and S. Priest (Eds.), Adventure programming (pp. 115-122). State College, PA: Venture Publishing.

Jacobs, J. A. (2004). An analysis of the effects of summer camp employment on emotional intelligence (Doctoral dissertation, University of Minnesota).

Jeruchim, J., \& Shapiro, P. G. (1992). Women, mentors, and success. Fawcett Columbine.

Kellert, S. (1999). A national study of outdoor wilderness experience. In R. Wizansky \& S. Reed (Eds.), new study demonstrates outdoor experience may prove life changing to adolescents, help solve education woes, The Outdoor Network, IX (4), 1-27.

King, D. H. (2000). Measurement of differences in emotional intelligence of preservice educational leadership students and practicing administrators as measured by the Multifactor Emotional Intelligence Scale.

Kirkpatick, S. A., \& Locke, E. A. (1991). Leadership: do traits matter?. Academy of management perspectives, 5(2), 48-60.

Kobe, L. M., Reiter-Palmon, R., \& Rickers, J. D. (2001). Self-reported leadership experiences in relation to inventoried social and emotional intelligence. Current Psychology, 20(2), 154-163.

Kolb, D. (1984). Experiential learning. Englewood Cliffs, NJ: Prentice-Hall.

Komives, S. R., Longerbeam, S., Owen, J. E., Mainella, F. C., \&Osteen, L. (2006). A leadership identity development model : Applications from a grounded theory. Journal of College Student Development, 47, 401-420.

Locke, EA. (1991). The Essence of Leadership: The Four Keys to Leading Successfully. New York Lexington Books. 
Lopes, P. N., Salovey, P., \& Straus, R. (2003). Emotional intelligence, personality, and the perceived quality of social relationships. Personality and individual Differences, 35(3), 641-658.

Marsh, H., Richards, G., \& Barnes, J. (1986). Multidimensional self-concepts: A long-term follow-up of the effect of participation in an Outward Bound Program. Personality and Social Psychology Bulletin, $12,475-492$.

Martin, B., Cashel, C., Wagstaff, M., \& Breunig, M. (2006). Outdoor Leadership: Theory and practice. Champaign, IL: Human Kinetics.

Mayer, J. D., Caruso, D. R., \& Salovey, P. (2000). Selecting a measure of emotional intelligence: The case for ability scales.

Mayer, J. D., Salovey, P., Caruso, D. R., \& Sitarenios, G. (2001). Emotional intelligence as a standard intelligence.

McCormick, M.J. (2001). Self-efficiency and Leadership Effectiveness: Applying social Cognitive Theory to Leadership. The Journal of Leadership Studies, 8(1), 22 - 33. http://doi.ord/10/1177/107179190100800102

Miner, J. (1999). The creation of outward bound. In J.C. Miles \& S. Priest (Eds.), Adventure programming (p.55-63). State College, PA: Venture Publishing.

Neill, J. (2007b). Factors which influence the effects of outdoor education programs. Guide to outdoor education research and evaluation. Retrieved April 13, 2009, from

http://www.wilderdom.com/research/researchfactors.html

NOLS Mission. (2021). About Us: Mission and values. Retrieved January 19th from http://www.nols.edu/about/values.shtml.

Palmer, B., Walls, M., Burgess, Z., \& Stough, C. (2001). Emotional intelligence and effective leadership. Leadership \& Organization development journal.

Parker, J. D. A., Creque, R. E., Barnhart, D. L., Harris, J. I., Majeski, S. A., Wood, L. M., (2004). Academic achievement in high school: Does emotional intelligence matter? Personality \& Individual Differences, 37(7), 1321-1330.

Paxton, T., \& McAvoy, L. (2000). Social psychological benefits of a wilderness adventure program. In S. McCool, D. Cole, W. Borrie, \& J. O'Loughlin (comps.) Wilderness science in a time of change conference, 3, 202-206; May 23-27 1999; Missuola, MT.

Prati, L. M., Douglas, C., Ferris, G. R., Ammeter, A. P., \& Buckley, M. R. (2003). Emotional intelligence, leadership effectiveness, and team outcomes. The international journal of organizational analysis.

Propst, D. B., \& Koesler, R. A. (1998). Bandura goes outdoors: Role of self-efficacy in the outdoor leadership development process. Leisure Sciences, 20(4), 319-344.

https://doi.org/10.1080/01490409809512289

Purkable, T. L. (2003). Emotional intelligence, leadership style and coping mechanisms of executives.

Raiola, E., \& O’Keefe, M. (1999). Philosophy in practice: A history of adventure programming. In, J.C. Miles \& S. Priest (Eds.). Adventure programming (pp. 45-53). State College, PA: Venture Publishing. 
Rink, J. 1985. Teaching physical education for learning. St. Louis: Times Mirror/Mosby..

Salovey, P., \& Mayer, J. D. (1990). Emotional intelligence. Imagination, cognition and personality, 9(3), 185-211.

Salovey, P. E., \& Sluyter, D. J. (1997). Emotional development and emotional intelligence: Educational implications. Basic Books.

Schulte, M. J. (2003). Emotional intelligence: A predictive or descriptive construct in ascertaining leadership style or a new name for old knowledge?

Seltzer, J., \& Bass, B. M. (1990). Transformational leadership: Beyond initiation and consideration. Journal of management, 16(4), 693-703.

Sibthorp, J., Paisley, K., \& Furman, N. (2008). Long-term impacts attributed to participation in wilderness education: preliminary findings from NOLS. Proceedings of the CEO conference, Bradford Woods, IN, January 13, 2008, 1-4.

Strayhorn, T. L., \& ebrary, I. (2012). College students' sense of belonging: A key to educational success for all students. New York; London; Routledge.

Stokes, M. E., C. S. Davis and G. G. Koch. 2012. Categorical Data Analysis using SAS®, Third Edition. Cary, NC: SAS Institute Inc.

Thorndike, E. L. Intelligence and its use. Harper's Magazine, 1920, 140, 227-235.

Webb, D. (1999). Recreational outdoor adventure programs. In, J.C. Miles and S. Priest (Eds.). Adventure programming (pp. 3-8). State College, PA: Venture publishing 


\section{Appendix A: Survey Instrument}

\begin{tabular}{|l|l|}
\hline D1 - What is your current class year? \\
\hline & Freshman \\
\hline & Sophomore \\
\hline & Junior \\
\hline & Senior \\
\hline & No longer a student \\
\hline
\end{tabular}

\begin{tabular}{|l|l|}
\hline D2 - What race/ethnic group(s) do you identity as? Please select all that apply. \\
\hline & American Indian or Alaskan Native \\
\hline & Asian \\
\hline & Black or African American \\
\hline & Hispanic or Latino \\
\hline & Native Hawaiian or other Pacific Islander \\
\hline & White or Caucasian \\
\hline & Prefer not to answer \\
\hline
\end{tabular}

D3 - What is your gender identity? There may be more than one answer that applies to you. Select the one that you feel best describes you or 'Prefer not to answer'

\begin{tabular}{|l|l|}
\hline & Female \\
\hline & Male \\
\hline & Cisgender \\
\hline & Transgender \\
\hline & Genderqueer or gender non-conforming \\
\hline & Another Identity \\
\hline & Prefer not to answer \\
\hline
\end{tabular}

D4 - Are you receiving financial aid from the university?

\begin{tabular}{|l|l}
\hline Yes \\
No
\end{tabular}

D5 - What year(s) were/are you a First Year Trip Leader for Adventure West Virginia? Please select all that apply. 


\begin{tabular}{|l|l|}
\hline & 2017 \\
\hline & 2018 \\
\hline & 2019 \\
\hline
\end{tabular}

\begin{tabular}{|l|l|}
\hline D6 - How many First Year Trips have you led? \\
\hline & $1-2$ Trips \\
\hline & $3-5$ Trips \\
\hline & $6-10$ Trips \\
\hline & $11-15$ Trips \\
\hline & $16+$ Trips \\
\hline
\end{tabular}

D7 - What position(s) did/do you hold with Adventure WV? Please select all that apply.

\begin{tabular}{|l|}
\hline Trip Leader - Front Country \\
\hline Trip Leader - Back Country \\
\hline Program Support Staff (logistics) \\
\hline Climbing Site Manager \\
\hline Outdoor Education Center Staff \\
\hline
\end{tabular}

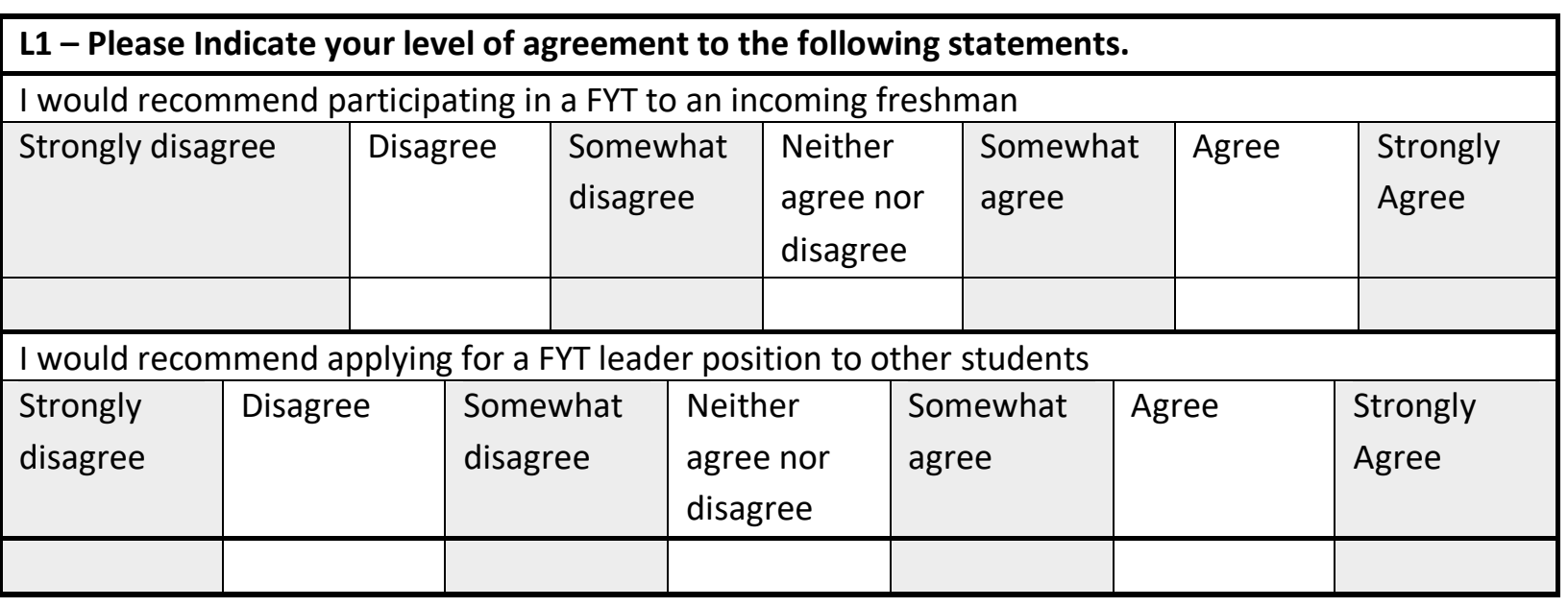

L2 - Please Indicate your level of agreement to the following statements.

Leading FYTs has had a tangible, positive impact on my leadership ability

\begin{tabular}{|l|l|l|l|l|l|l|}
\hline Strongly disagree & Disagree & $\begin{array}{l}\text { Somewhat } \\
\text { disagree }\end{array}$ & $\begin{array}{l}\text { Neither } \\
\text { agree nor } \\
\text { disagree }\end{array}$ & $\begin{array}{l}\text { Somewhat } \\
\text { agree }\end{array}$ & $\begin{array}{l}\text { Agree } \\
\text { Agree }\end{array}$ \\
\hline & & & & & & \\
\hline
\end{tabular}




\begin{tabular}{|l|l|l|l|l|l|l|}
\hline L3 - How would you rate your leadership skills compared to other WVU students? \\
\hline Far below average & $\begin{array}{l}\text { Below } \\
\text { Average }\end{array}$ & $\begin{array}{l}\text { Slightly } \\
\text { below } \\
\text { average }\end{array}$ & Average & $\begin{array}{l}\text { Slightly } \\
\text { above } \\
\text { average }\end{array}$ & $\begin{array}{l}\text { Moderately } \\
\text { Above } \\
\text { Average }\end{array}$ & $\begin{array}{l}\text { Far Above } \\
\text { Average }\end{array}$ \\
\hline & & & & & \\
\hline
\end{tabular}

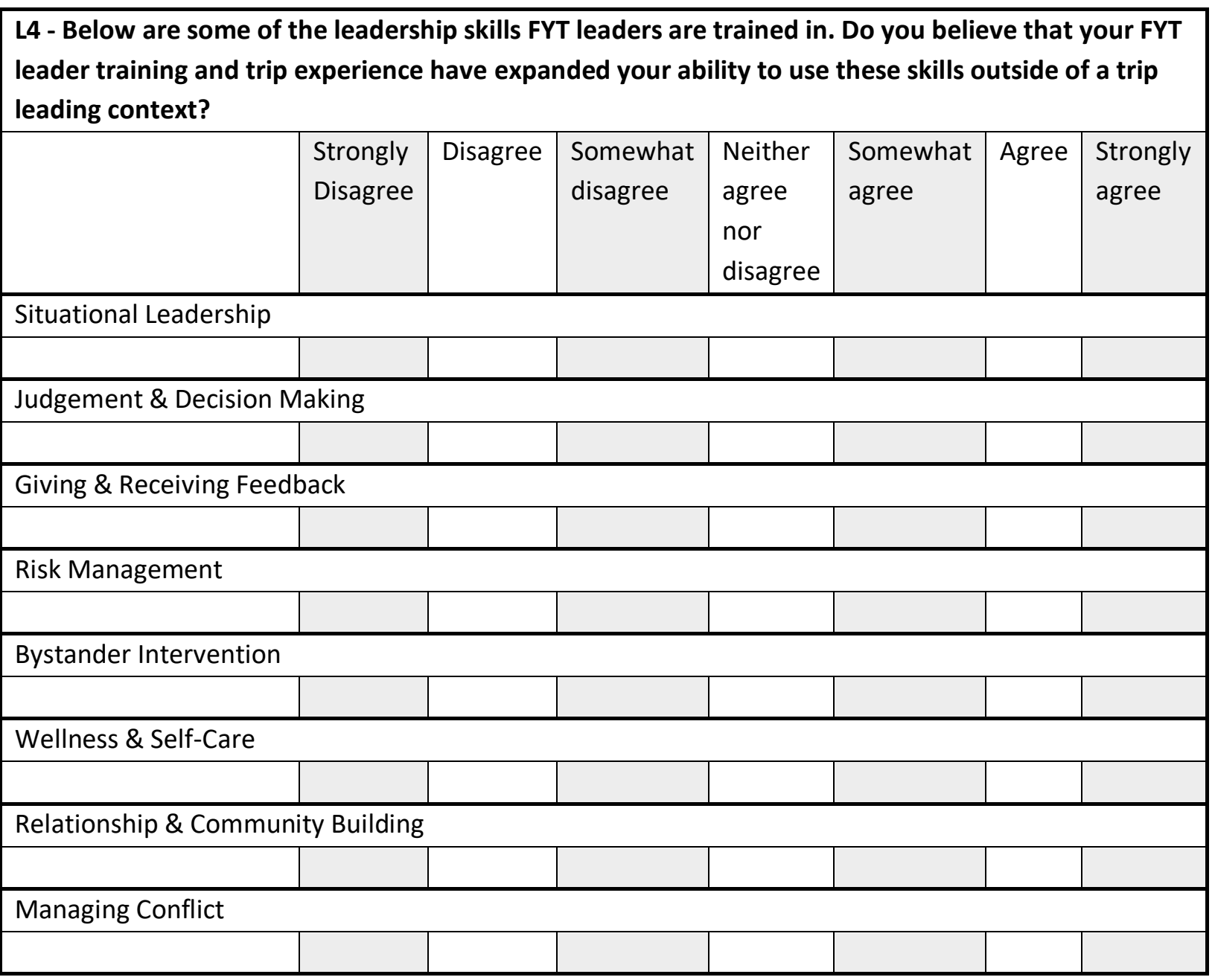

L5 - Please rank the following categories based on how impactful leading for Adventure WV was for your growth in each of these categories. 1 = most impactful, 8 = least impactful

\begin{tabular}{|l|l|}
\hline & Situational Leadership \\
\hline & Judgement \& Decision Making \\
\hline & Giving \& Receiving Feedback \\
\hline & Risk Management \\
\hline & Bystander Intervention \\
\hline & Wellness \& Self-Care \\
\hline
\end{tabular}




\begin{tabular}{|l|l|}
\hline & Relationship \& Community Building \\
\hline & Managing Conflict \\
\hline
\end{tabular}

\begin{tabular}{|c|c|c|c|c|c|c|c|}
\hline \multicolumn{8}{|c|}{$\begin{array}{l}\text { L6 - Have the Leadership Skills/Experiences that you have learned through Adventure WV been } \\
\text { useful in working with populations or settings outside of Adventure WV? }\end{array}$} \\
\hline & \begin{tabular}{|l|} 
Strongly \\
Disagree
\end{tabular} & Disagree & $\begin{array}{l}\text { Somewhat } \\
\text { disagree }\end{array}$ & $\begin{array}{l}\text { Neither } \\
\text { agree } \\
\text { nor } \\
\text { disagree }\end{array}$ & $\begin{array}{l}\text { Somewhat } \\
\text { agree }\end{array}$ & Agree & $\begin{array}{l}\text { Strongly } \\
\text { agree }\end{array}$ \\
\hline \multicolumn{8}{|c|}{ In the Community outside of WVU } \\
\hline \multicolumn{8}{|c|}{ Within Student Groups } \\
\hline & & & & & & & \\
\hline \multicolumn{8}{|c|}{ With Friends/Roommates } \\
\hline & & & & & & & \\
\hline \multicolumn{8}{|c|}{ With Family Members } \\
\hline & & & & & & & \\
\hline \multicolumn{8}{|l|}{ In the Workplace } \\
\hline & & & & & & & \\
\hline
\end{tabular}

\begin{tabular}{|l|l|l|l|l|l|l|}
\hline L7 - Please answer the following statements. \\
\hline & \multicolumn{2}{|l|}{ While leading FYTs, I am able to... } & \multicolumn{2}{|l|}{ Outside of FYTs, I am able to... } \\
& Not True & $\begin{array}{l}\text { Somewhat } \\
\text { True }\end{array}$ & $\begin{array}{l}\text { Very } \\
\text { True }\end{array}$ & No True & $\begin{array}{l}\text { Somewhat } \\
\text { True }\end{array}$ & $\begin{array}{l}\text { Very } \\
\text { True }\end{array}$ \\
\hline understand my emotions & & & & & & \\
\hline read people and their emotions & & & & & & \\
\hline manage my emotions effectively & & & & & & \\
\hline $\begin{array}{l}\text { manage others' emotions } \\
\text { effectively }\end{array}$ & & & & & & \\
\hline $\begin{array}{l}\text { achieve goals that I set for } \\
\text { myself }\end{array}$ & & & & & & \\
\hline $\begin{array}{l}\text { set long term goals and review } \\
\text { my progress regularly }\end{array}$ & & & & & & \\
\hline
\end{tabular}

